\title{
Dinheiro, Tempo e Memória Eleitoral: Os Mecanismos que Levam ao Voto nas Eleições para Prefeito em 2012
}

\author{
Bruno Wilhelm Speck ${ }^{1}$ \\ Emerson Urizzi Cervi ${ }^{2}$ \\ 1. Universidade de São Paulo (USP). São Paulo, SP, Brasil. E-mail: bruno.speck@gmail.com. \\ 2. Universidade Federal do Paraná (UFPR). Curitiba, PR, Brasil. E-mail: ecervi7@gmail.com.
}

\section{INTRODUÇÃO}

$\mathrm{O}$ tema central deste artigo é a importância dos recursos mobilizados nas campanhas eleitorais para a eleição para prefeito em 2012, controlando-se por outros fatores contextuais. Usamos regressão linear para identificar o valor explicativo dos vários fatores e análise de trajetória para identificar os mecanismos causais que ligam as diferentes explicações ao desempenho eleitoral. Entendemos como desempenho eleitoral a porcentagem de votos conquistados pelo candidato à prefeitura. Incluímos na nossa definição de recursos o dinheiro declarado de arrecadação de campanha e o tempo de horário eleitoral no rádio e na TV. Ambos entram no modelo como variáveis independentes. Como variável de controle usamos os resultados da eleição municipal anterior - a de 2008. Consideramos que partidos que já disputaram eleições anteriores e que foram bem votados conseguem manter uma "memória" eleitoral positiva nas disputas futuras. Finalmente, levamos em conta o tamanho dos municípios como variável mediadora, presumindo que a dinâmica das eleições e o peso dos fatores acima variam com o tamanho dos municípios.

Estes cinco fatores explicativos são mobilizados para buscar respostas às seguintes perguntas: Qual é o peso do dinheiro e do tempo de propa-

DADOS - Revista de Ciências Sociais, Rio de Janeiro, vol. 59, n- 1, 2016, pp. 53 a 90. 
ganda gratuita para a votação dos candidatos a prefeito na eleição municipal? A votação do candidato depende do desempenho do seu partido na última eleição? A relação desses fatores com o desempenho eleitoral dos candidatos é idêntica em municípios pequenos, médios e grandes?

A partir daqui o texto está dividido em quatro partes. Na primeira apresentamos as principais características da discussão presente na literatura em Ciência Política sobre a influência de recursos financeiros e não financeiros em campanhas eleitorais, bem como sobre as outras variáveis de controle. Em seguida, apresentamos os dados, detalhando a operacionalização das variáveis. Também descrevemos o modelo de análise e as principais hipóteses do artigo. Na terceira parte, discutimos os resultados dos testes da regressão linear multivariada, bem como os da análise de trajetória e, por fim, recapitulamos os resultados e traçamos conclusões a respeito das características das eleições municipais no Brasil e do emprego de diferentes técnicas de análise para a compreensão dos processos causais envolvidos.

\section{CAUSAS E CONDICIONANTES DO DESEMPENHO ELEITORAL}

Começamos com a discussão individual de cada uma das variáveis e o seu lugar na investigação acadêmica atual.

\section{Recursos Financeiros}

Os recursos financeiros mobilizados em campanhas eleitorais brasileiras e a disponibilidade desses dados em formato eletrônico têm incentivado o estudo da relação entre dinheiro e voto no Brasil. A pesquisa sobre a importância do dinheiro para o desempenho eleitoral tem curta, mas marcante, tradição no Brasil. Vários trabalhos publicados na última década se propõem a medir a importância do dinheiro para o sucesso eleitoral (Cervi, 2010; Figueiredo Filho, 2009; Heiler, 2011; Peixoto, 2010, Pereira e Rennó, 2011; Samuels, 2001, 2002; Santos, 2011; Speck e Mancuso, 2011, 2013, 2014). Outras duas linhas de investigação se referem à explicação dos recursos arrecadados. Autores como Jones (1981), Rosen (1981), Taagepera e Shugart (1989) e, para o caso brasileiro, Braga e Boudourkan (2009), Heiler (2011), Peixoto (2010) e Silveira e Mello (2011) perguntam quais seriam os fatores que dinamizam a demanda e/ou a oferta de recursos nas campanhas eleitorais. Nesta segunda indagação, o financiamento é a variável depen- 
dente. Uma terceira linha se refere aos trabalhos que analisam o impacto do financiamento sobre o comportamento dos eleitos e as políticas públicas adotadas. Esta terceira linha conta com menos trabalhos, apesar de gozar de grande visibilidade no debate público (Boas, Hidalgo e Richardson, 2014; Claessens, Feijen e Laeven, 2008). Este texto diz respeito às primeiras duas indagações. Como veremos adiante, o nosso modelo inclui tanto a discussão sobre se o volume de recursos arrecadados influencia o desempenho eleitoral como também se este volume, por sua vez, sofre influência de outros fatores.

\section{Tempo de Propaganda Gratuita}

Uma das características perenes do processo eleitoral brasileiro é a garantia de acesso gratuito a rádio e TV pelos competidores, em combinação com a proibição de propaganda paga nesses mesmos meios (Jorge, 1997; Speck, 2005). Esse modelo de "propaganda eleitoral pública exclusiva" obriga as emissoras de rádio e TV a reservar uma hora diária durante seis semanas antes das eleições à veiculação da propaganda eleitoral, um espaço generoso em relação a outros países com modelos similares. O recurso "tempo" tem grande impacto sobre a dinâmica da disputa eleitoral nacional e estadual em função da presença praticamente universal do acesso a rádio e TV no Brasil (com cobertura em 2010 de $81,4 \%$ e $95,0 \%$ dos domicílios, respectivamente) (Speck e Campos, 2014:15).

Porém, nas eleições municipais, a influência da mídia eletrônica sobre a política local depende da possibilidade de veicular a propaganda eleitoral. Isto nem sempre é o caso. Para que o horário eleitoral gratuito influencie a dinâmica das eleições locais, é necessário que as estações de rádio e eventualmente também as emissoras de TV veiculem a propaganda dos candidatos locais. $\mathrm{O}$ acesso dos partidos à propaganda local depende de uma combinação de dois fatores: a infraestrutura de comunicação disponível no município e a legislação eleitoral regulando o acesso e distribuição do tempo de propaganda. Nos municípios sem emissora de rádio e/ou TV própria os cidadãos têm acesso à propaganda eleitoral de outros municípios. Adisputa local fica sem cobertura oficial no rádio, TV ou em ambos.

Levando em conta o critério da infraestrutura disponível, o quadro da cobertura de rádio e TV para as eleições locais é peculiar. Somente $68 \%$ dos municípios brasileiros analisados aqui dispõem de estações pró- 
prias de rádio e menos de $4 \%$ dos municípios têm uma estação de TV com produção própria ${ }^{1}$. A legislação eleitoral brasileira determina que emissoras de rádio e TV transmitam o horário eleitoral dos candidatos do município em que se encontra o transmissor. No Brasil, 205 municípios têm pelo menos um transmissor de TV e 3.572 municípios contam com pelo menos uma emissora de rádio, o que representa $68,4 \%$ do total analisado aqui. Em todos os municípios com estações próprias de rádio ou $\mathrm{TV}$, as emissoras devem veicular gratuitamente a propaganda eleitoral dos partidos e candidatos ${ }^{2}$. Nos municípios acima de $200 \mathrm{mil}$ habitantes (com eleições em dois turnos), a justiça eleitoral tenta viabilizar a transmissão do horário eleitoral gratuito nas estações de TV, mesmo que o local não disponha de emissoras próprias ${ }^{3}$.

Na prática esta combinação entre infraestrutura e lei resulta em três situações diferentes em relação ao acesso à propaganda gratuita pelos cidadãos. Primeiro, os municípios que não contam com infraestrutura própria e não recebem propaganda dos candidatos locais. Via de regra, os eleitores desses locais recebem o horário eleitoral dos municípios vizinhos que sediam estações de rádio ou transmissoras de TV. Um segundo grupo de municípios possui estações de rádio próprias, que transmitem a propaganda das eleições locais, mas recebem a propaganda de TV de outro município por não existir transmissor de TV local. No terceiro grupo estão os municípios onde estações de rádio e transmissoras de TV garantem a veiculação da propaganda eleitoral gratuita dos candidatos locais pelos dois canais ${ }^{4}$. A distribuição numérica dessas situações no universo dos municípios brasileiros se dá na seguinte forma: no primeiro grupo estão $33 \%$ dos municípios, no segundo grupo, $63 \%$, e no terceiro grupo, $4 \%$.

A nossa análise se estende aos três grupos de municípios: locais sem propaganda própria, locais com propaganda própria somente em rádio, e locais com propaganda política local via rádio e TV. No final do artigo replicamos o modelo de análise para os municípios do segundo grupo somente (presença do horário eleitoral exclusivamente em rádio). Os trabalhos sobre o tempo de propaganda em rádio e TV são mais escassos em comparação com os específicos sobre o financiamento (Jardim, 2004; Schmitt, Carneiro e Kuschnir, 1999). Sabemos que os próprios operadores políticos valorizam esse tempo e os comentaristas enfatizam a importância do espaço publicitário para a formação das coalizões. Mas há poucos esforços para medir o peso do horário para o 
sucesso eleitoral (Bolognesi e Cervi, 2011; Cervi, 2011; Dantas, 2012; Silveira e Mello, 2011) $)^{5}$.

O objetivo deste artigo é quantificar a importância dos recursos nas duas modalidades "dinheiro" e "tempo" no rádio e na TV (variáveis independentes) para o voto dos candidatos (variável dependente). Não conhecemos outras tentativas de ver os dois fatores em paralelo.

\section{Memória Eleitoral}

A questão da "memória eleitoral" do partido como determinante da votação é menos óbvia. A pesquisa eleitoral tem dado destaque à falta de fidelização no contexto das eleições brasileiras em todos os níveis. A Ciência Política interpreta as altas taxas de volatilidade no Brasil em comparação com outros países como um indicador da baixa fidelização do eleitor brasileiro com determinadas siglas partidárias. Vários cientistas políticos usaram a alta volatilidade como indicador para o fraco enraizamento dos partidos no eleitorado (Bohn e Paiva, 2009; Kinzo, 2005; Mainwaring, 1995, 1998).

Outro argumento contra a fidelização às siglas partidárias é que os eleitores se identificariam mais com os candidatos do que com os partidos pelos quais eles disputam as eleições. Principalmente nos pequenos municípios o personalismo na relação entre eleitor e classe política tornaria secundárias as siglas partidárias.

Partindo dessas teses sobre a volatilidade e o personalismo, esperaríamos um impacto bastante reduzido da memória eleitoral sobre as próximas eleições. A despeito dessas expectativas negativas, usaremos a votação na eleição municipal anterior como variável explicativa no nosso modelo. Mostraremos que, para fins de previsão do resultado eleitoral de determinada eleição, os resultados do pleito anterior ainda são um dos preditores mais fortes (Almeida e Carneiro, 2003).

A reconstrução da memória eleitoral é uma tarefa complexa. No contexto das eleições municipais, onde candidatos frequentemente mudam de partido entre duas eleições, uma primeira decisão é se a memória está vinculada ao partido ou ao candidato. A próxima decisão é se devemos levar em conta somente o padrão de votação para o mesmo cargo, ou se incluímos outras formas de memória eleitoral, como, por exemplo, o reconhecimento do nome de um candidato em função da disputa de uma outra eleição (para deputado estadual ou federal, por 
exemplo). Da mesma forma poderíamos incluir a votação do partido para outros cargos. A mobilização de apoio de outros partidos através de coalizões é outro fator relevante, tanto em função do apoio direto como também em função do impacto do número de candidatos sobre a estrutura da competição. Entre essas diferentes possibilidades de operacionalizar a memória eleitoral, optamos pelo enfoque no partido, na disputa pelo mesmo cargo, incluindo aqui também o capital eleitoral dos partidos da coligação que apoia o candidato a prefeito.

\section{Contextos Paroquiais e Metropolitanos}

Adicionalmente, queremos saber se o peso das variáveis dinheiro de campanha, tempo e memória de votação sobre o desempenho eleitoral depende do tamanho do município. Suspeitamos que disputas políticas em municípios pequenos, médios e grandes, que ocorrem em contextos socioeconômicos e políticos diferentes, sigam dinâmicas diferentes. Vários trabalhos apontaram para os padrões persistentes de personalismo e mandonismo na política local (Barreto, 2009; Almeida e Lopez, 2014; Kerbauy, 2000). A maioria dos estudos sobre os partidos políticos enquanto organizações que estruturam a oferta de candidatos e orientam a escolha eleitoral se ocupou do âmbito nacional e estadual da política, mas o número de contribuições sobre a política local está crescendo (Almeida e Carneiro, 2003; Avelar e Lima, 2000; Avelar e Walter, 2008; Carneiro e Almeida, 2008; Fleischer, 2002; Kerbauy, 2000; Lavareda e Telles, 2011). Recentemente vários trabalhos em Speck e Brasiliense (2013) sobre as eleições municipais 2012 mostraram que a dinâmica da disputa eleitoral varia dependendo do tamanho dos municípios. Mesmo que os limites entre "municípios paroquiais", "centros urbanos" e "metrópoles" não estejam claramente definidos, temos uma ideia a respeito da qualidade diferente das relações interpessoais e do papel da mídia nesses ambientes, além dos seus impactos sobre a disputa eleitoral. Queremos abrir o debate sobre este tema, quantificando as diferenças entre os fatores determinantes do desempenho eleitoral entre municípios de diferentes tamanhos.

Esperamos que em municípios pequenos o contato direto entre candidato e eleitor seja mais importante, em detrimento de formas intermediadas de comunicação como rádio e TV. Também é razoável esperar que o contato direto entre cidadãos e candidatos diminua o papel dos partidos como sinalizadores da qualidade dos candidatos. No ambiente da política paroquial as relações pessoais e o contato direto entre políticos e cidadãos se sobrepõem à influência do dinheiro, da mídia e da 
identificação partidária. Esperamos que a previsibilidade do desempenho eleitoral a partir dessas variáveis explicativas seja menor em contextos de disputas paroquiais.

Nos municípios maiores o efeito dessa cultura da política local é transformado pelo acesso aos meios de comunicação, mais especificamente à transmissão de programação de rádio e TV. O peso do horário eleitoral aumenta em função do peso da mídia eletrônica como canal de comunicação política em municípios grandes. Também esperamos um peso maior da memória eleitoral sobre o desempenho no pleito seguinte. Com a ausência de informações diretas sobre os candidatos, o papel de sinalizadores para orientação dos eleitores e doadores aumenta. Uma das informações importantes é o acolhimento de uma candidatura por um partido capaz de produzir sucesso eleitoral no município. Nesse contexto da ação estratégica dos atores políticos, o desempenho eleitoral no passado se torna importante.

\section{BASE DE DADOS E OPERACIONALIZAÇÃO DAS VARIÁVEIS}

Em 2012 o Brasil elegeu prefeitos para 5,6 mil municípios. Para isso, os partidos apresentaram cerca de 14 mil candidatos às prefeituras, o que significa uma média de cerca de três candidatos a prefeito por município. Em municípios menores a concorrência cai, ficando abaixo de dois em média por vaga e, em municípios maiores, acima de 50 mil eleitores, a média de candidatos sobe para quase quatro.

Incluímos no banco de dados somente as candidaturas a prefeito que foram deferidas (sem ressalvas) pela justiça eleitoral. Como estamos considerando as votações na disputa anterior, em 2008, excluímos do nosso banco de dados os novos municípios, criados entre 2009 e 2012, e que, portanto, não tinham tido eleição anterior. Também excluímos outros municípios para os quais não obtivemos dados completos sobre a presença de estações de rádio ou TV. Finalmente, tiramos da nossa base as disputas não competitivas. Incluímos nesta categoria eleições nas quais um candidato obteve mais que $95 \%$ dos votos, dos recursos ou do tempo de propaganda. Com isso, analisamos aqui as eleições de 4.888 municípios ${ }^{6}$. Disputaram eleições para prefeito nesses municípios 13.038 candidatos em 2012. Ao todo, 29 partidos apresentaram candidatos aos executivos municipais. A Tabela 1 informa a distribuição dos municípios e dos candidatos entre as três categorias de acesso à propaganda gratuita e cinco categorias referentes ao tamanho do eleitorado dos municípios. 
Tabela 1

Distribuição dos Municípios e dos Candidatos em Função do Acesso à Propaganda Eleitoral

\begin{tabular}{l|c|c|c|c}
\hline & N & $\begin{array}{c}\text { Sem Propaganda } \\
\text { Própria }\end{array}$ & $\begin{array}{c}\text { Propaganda } \\
\text { somente no Rádio }\end{array}$ & $\begin{array}{c}\text { Propaganda em } \\
\text { Rádio e TV }\end{array}$ \\
\hline Municípios & $\mathbf{( 4 . 8 8 8 )}$ & $33 \%(1.613)$ & $62 \%(3.030)$ & $5 \%(245)$ \\
Candidatos & $\mathbf{( 1 3 . 0 3 8 )}$ & $30 \%(3.911)$ & $63 \%(8.213)$ & $7 \%(914)$ \\
\hline
\end{tabular}

Fonte: Elaboração própria a partir de dados do TSE.

Construímos uma base única de dados com variáveis a respeito do dinheiro gasto na campanha, do tempo de rádio e TV e dos votos no primeiro turno para os mais de 13 mil candidatos que chegaram ao final da disputa para prefeito nas eleições municipais em 2012 e prestaram contas das finanças de campanha dentro do prazo estipulado pelo Tribunal Superior Eleitoral (TSE). Esta base de dados foi construída a partir das informações disponíveis no repositório dos dados eleitorais do $(\mathrm{TSE})^{7}$. A construção das variáveis será apresentada a seguir.

\section{Desempenho ou Sucesso Eleitoral?}

Os estudos recorrem a duas medições diferentes para aferir o resultado eleitoral. Uma alternativa é a medição do sucesso a partir da vitória ou derrota do candidato, outra leva em conta o desempenho a partir da porcentagem de votos alcançados. Ambas as formas de operacionalizar sucesso ou desempenho se baseiam em duas interpretações diferentes da eleição. Como instrumentos heurísticos, eles têm pontos fortes e fraquezas. Aqui escolhemos usar o desempenho eleitoral como forma de operacionalizar o resultado eleitoral. Esta também permite aplicar a análise de trajetória como técnica de pesquisa complementar à regressão linear multivariada. O desempenho dos candidatos a prefeito nas eleições 2012 é operacionalizado a partir da porcentagem de votos obtida no primeiro turno sobre o total de votos válidos. Como menos de $2 \%$ dos municípios brasileiros têm mais de 200 mil eleitores e segundo turno, aqui analisaremos apenas os resultados do primeiro turno das eleições municipais brasileiras.

\section{Refinando o Valor do Dinheiro Gasto na Campanha}

Em relação aos gastos dos candidatos, duas importantes transformações foram aplicadas aos dados disponibilizados pelo TSE. A primeira transformação se refere à soma das prestações de contas de "candida- 
tos a prefeito" com as contas dos "comitês dos candidatos a prefeito" O sistema de prestação de contas sobre os gastos eleitorais prevê três modalidades de prestação de contas: cada candidato pode prestar contas individualmente, candidatos podem criar comitês eleitorais, prestando contas individualmente ou em bloco, e partidos políticos prestam contas sobre as suas despesas. Enquanto a maioria dos estudos se contenta com as despesas informadas por candidato, desconsiderando os gastos declarados pelos comitês e pelos partidos, apresentamos aqui uma solução que se aproxima mais dos gastos reais dos candidatos. Esta soma dos gastos de candidatos e comitês retrata a totalidade de recursos mobilizados pelos candidatos a prefeito.

A segunda transformação corrige um problema de inflação dos gastos eleitorais em função de transferências de recursos entre várias contas. Como candidatos, comitês e partidos podem transferir recursos entre si durante a campanha, a mera soma das diferentes contas resulta em duplicação de valores. Trabalhamos com os gastos efetivos, descontando eventuais transferências dos candidatos a outros correligionários ou ao partido político.

Falta ainda um terceiro passo para chegar à porcentagem dos recursos. Baseados nos dados sobre a soma dos gastos efetivos de comitês e candidatos, calculamos o valor total de recursos aplicados em cada município pelo conjunto dos candidatos. A variável despesa de candidatos é calculada como porcentagem dos gastos efetivos de cada candidato sobre este valor total mobilizado no município pelos concorrentes.

\section{Calculando o Tempo dos Candidatos no Horário Eleitoral}

O horário gratuito de propaganda eleitoral (HGPE) é distribuído segundo as regras acima explicitadas, que foram reproduzidas no cálculo da variável. Em relação à identificação dos municípios que dispõem de transmissão de propaganda política, foi necessário reconstruir o dado a partir de várias fontes, uma vez que a justiça eleitoral não dispõe de um registro central a respeito da transmissão de fato do horário eleitoral nos municípios. Para a transmissão do horário eleitoral próprio via rádio, nos baseamos em um levantamento realizado em 2006 pelo IBGE a respeito da presença de emissoras de rádio 9 . Para a questão da presença de emissoras de TV, recorremos aos dados da Anatel de 2013 sobre a localização das emissoras e retransmissoras das empresas de rádio e TV no Brasil ${ }^{10}$. As variáveis do horário eleitoral incluem in- 
formações sobre o tempo de rádio e TV disponível para cada uma das 13 mil candidaturas inseridas no nosso banco de dados. O tempo de rádio disponível para cada candidato foi novamente calculado como percentagem sobre o total de tempo disponível para todos os candidatos no mesmo município ${ }^{11}$.

\section{Escolhendo entre Diferentes Memórias Eleitorais}

Após a decisão de incluir a memória eleitoral como variável de controle, uma das questões importantes é definir se comparamos a fidelização em nomes de políticos ou em siglas partidárias. Nos casos em que os mesmos candidatos concorrem pelo mesmo partido ao mesmo cargo de prefeito em duas eleições subsequentes, não há diferença entre as duas estratégias. Em outros casos os candidatos mudam de partido entre duas eleições, não concorrem mais ou são impedidos de concorrer, porque já exerceram dois mandatos. Por mais que o personalismo seja um fator importante na política local, os nomes de políticos são menos perenes do que as siglas partidárias. Por este motivo, optamos por focar na memória eleitoral referente à sigla partidária.

O histórico da votação dos candidatos foi calculado com base na porcentagem de votos válidos depositados para os partidos dos candidatos a prefeito na eleição municipal anterior (2008). Para comparação com os resultados da eleição de 2012 foram somadas as porcentagens de voto na eleição passada para prefeito de todos os partidos que integraram a coligação para prefeito em $2012^{12}$. Pressupomos que os partidos da coligação dos candidatos em 2012 conseguem mobilizar o capital político das eleições anteriores para as atuais eleições. A variável está disponível como porcentagem de votos dos partidos em 2008 agrupadas nas coligações de 2012.

\section{Identificando Ambientes Paroquiais e Metropolitanos}

Uma das questões abordada aqui é se determinados mecanismos causais que explicam o voto no Brasil dependem do contexto. Em termos técnicos estamos falando do efeito moderador de uma variável sobre a relação entre duas outras variáveis. Esta moderação de efeitos causais por variáveis intervenientes pode ser analisada recorrendo a diferentes estratégias de análise. Uma delas é a inserção de efeitos de interação nas regressões, como, por exemplo em Speck e Mancuso (2014). Outra é a análise detalhada das relações entre as variáveis em um siste- 
ma de equações. Aqui empregamos uma combinação dessas duas estratégias.

O nosso modelo inicial parte do pressuposto de que o tamanho do município importa para a dinâmica eleitoral (e mais especificamente para a forma como as variáveis dinheiro, tempo e memória se relacionam para influenciar o voto). Por outro lado, não temos uma teoria sobre os limites de tamanho entre municípios que poderíamos chamar de paroquiais, urbanos ou metropolitanos. Na falta de tal teoria classificamos os municípios por tamanho em cinco grupos, com cortes em 5 mil, 10 mil, 50 mil e 200 mil eleitores.

\section{As Hipóteses}

Esperamos que tanto o dinheiro gasto na campanha como o horário eleitoral tenham influência sobre o sucesso nas urnas. A alocação de mais dinheiro (variável "dinheiro") e mais tempo de rádio e TV (variável "tempo") deveriam resultar em mais votos (variável "voto"), uma vez que esses dois recursos são considerados decisivos para a disputa eleitoral pelos próprios atores envolvidos. A nossa pergunta é: o que conta mais? É mais importante ter mais gastos eleitorais ou ter tempo para a propaganda gratuita? A nossa primeira hipótese é que o recurso tempo tem um peso similar ao recurso dinheiro.

A segunda hipótese se refere ao detalhamento de mecanismos causais que atuam ligando os diferentes fatores mobilizados ao desempenho eleitoral. Sabemos que os ciclos eleitorais estão interligados e que tanto padrões de comportamento dos eleitores ou dos partidos como também fatores institucionais interligam as eleições anteriores às atuais. Elaboramos um modelo de análise (Gráfico 1) que representa essas relações causais.

Em primeiro lugar o nosso modelo inclui (a) as relações diretas entre dinheiro, tempo e memória. Como todas as nossas variáveis são calculadas em porcentagem, o número de candidatos participando na eleição tem um efeito importante sobre os valores. Para corrigir este efeito incluímos uma variável "competitividade" (que representa o número de candidatos disputando a prefeitura em cada município) no modelo. Esperamos que as variáveis dinheiro e tempo tenham um efeito forte e similar sobre o voto; que a memória eleitoral influencie pouco os votos e que a competitividade tenha um efeito negativo (quanto mais candidatos, menor a porcentagem média para cada concorrente) sobre os 
Gráfico 1

O Modelo de Análise

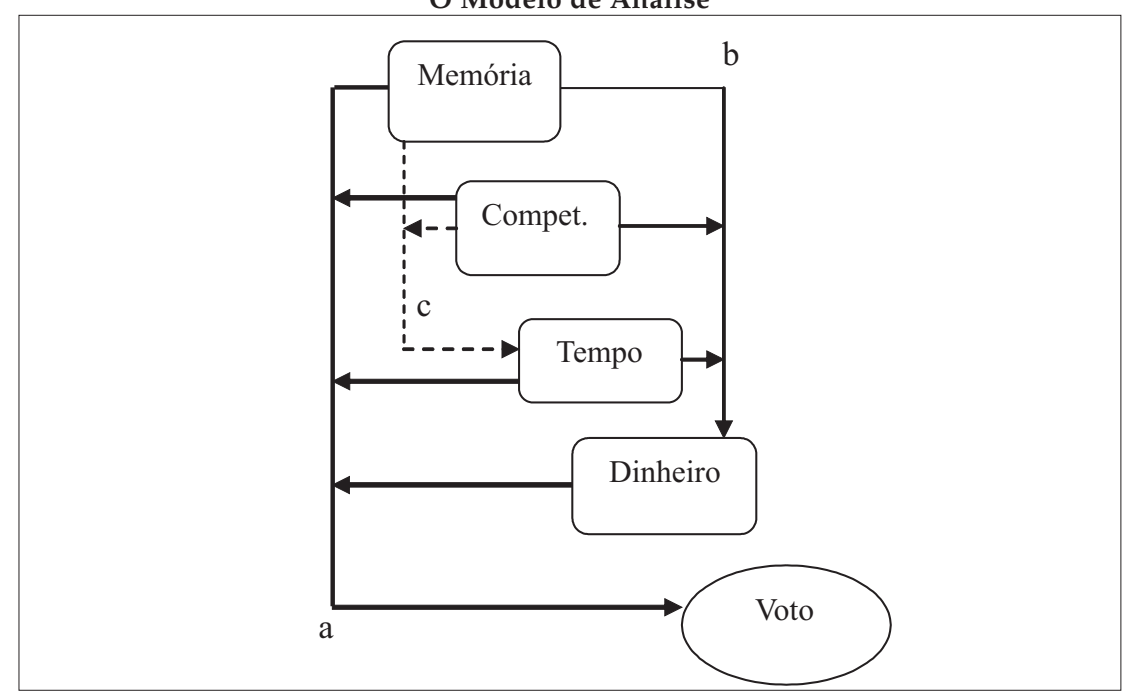

Fonte: Elaboração própria das variáveis eleitorais incidentes sobre o voto.

votos. Este efeito mecânico é de menor interesse analítico para nosso propósito, mas essencial para o modelo.

Em segundo lugar temos (b) os efeitos do tempo, da memória e da competitividade sobre o dinheiro (e por meio deste, de forma indireta, sobre o voto). Esperamos que o tempo de propaganda disponível dinamize a arrecadação de recursos, porque os candidatos em municípios com propaganda eleitoral devem ter mais gastos eleitorais. Apesar da gratuidade da veiculação da propaganda eleitoral, a produção das peças publicitárias a serem veiculadas em rádio e TV gera custos adicionais. Quanto maior o tempo gratuito, maior a necessidade de investimento adicional para preencher o espaço com propaganda de qualidade.

Adicionalmente, esperamos que o volume de recursos arrecadados tenha relação com o fator memória eleitoral. Esperamos que os doadores atuem de forma estratégica na alocação de recursos, apoiando preferencialmente candidatos que tenham alguma chance de chegar a um bom resultado eleitoral. Um dos indicadores probabilísticos para o bom desempenho na eleição presente é o desempenho na eleição anterior. A análise mais detalhada dessa relação joga luz sobre a questão clássica da pesquisa sobre financiamento: se o gasto eleitoral gera votos ou se a expectativa de votos gera arrecadação de recursos. 
Em terceiro lugar há (c) um conjunto de efeitos políticos e regras institucionais que vinculam o desempenho na última eleição ao horário gratuito na próxima. O efeito político passa pela influência dos partidos disputando a eleição municipal sobre o próximo pleito nacional, por exemplo. Especificamente os vereadores e o prefeito eleitos são agentes poderosos, no município, para a mobilização da campanha para a eleição de deputados estaduais e federais nas eleições nacionais entre duas eleições municipais.

O efeito político é complementado por um efeito institucional. As regras de alocação da propaganda gratuita vinculam a eleição passada à próxima. Porém, não há vínculo direto entre o resultado da eleição municipal com o horário eleitoral na eleição municipal atual. O principal parâmetro para a alocação do tempo é a eleição para a Câmara dos Deputados $^{13}$. Da forma que a distribuição do tempo de rádio e TV estava regulada em 2012 pela legislação eleitoral ${ }^{14}$, um terço do horário eleitoral gratuito é alocado de forma igualitária entre os partidos ou coalizões do distrito eleitoral, no nosso caso, em cada município. A maior parte dos recursos (dois terços) é distribuída conforme o peso eleitoral dos partidos no âmbito nacional, mais especificamente em função do número de representantes do partido na Câmara dos Deputados imediatamente após a última eleição ${ }^{15}$. A soma destas duas regras de alocação dos recursos resultará em uma distribuição específica do tempo de propaganda em cada município ${ }^{16}$. A eleição municipal e o tempo de propaganda estão vinculados, ainda que os mecanismos de vinculação sejam imprecisos e intermediados. Vamos aferir a intensidade desta relação a seguir. A nossa hipótese é que a correlação é baixa em função dos fatores intermediários discutidos antes. A análise de trajetória é uma ferramenta importante para jogar luz sobre os mecanismos causais neste modelo. Como método confirmatório ele mostra como mecanismos causais que estão por trás da correlação podem ser desagregados, destacando a contribuição direta e indireta de cada fator sobre o voto.

A terceira hipótese é que as relações entre diferentes variáveis não podem ser replicadas em municípios de diferentes tamanhos. Esperamos que, entre a política paroquial e as metrópoles, o peso relativo destes fatores para explicar o desempenho eleitoral seja distinto. Para analisar esta questão incluímos interações no nosso modelo inicial, para averiguar se o peso do dinheiro, do tempo e da memória muda em função do tamanho dos municípios. Esperamos um resultado significati- 
vo nestas interações. Em relação à direção da interação, esperamos que ela seja positiva em relação ao dinheiro, ao tempo e à memória (dinheiro e propaganda importam mais nos grandes municípios e os eleitores se fidelizam menos).

No próximo tópico faremos as análises estatísticas com base nas variáveis descritas até aqui. A partir daqui o artigo será dividido em duas partes: na primeira, apresentamos uma análise descritiva dos resultados. Em seguida, demonstramos os modelos de análise de trajetória por grupo de municípios.

\section{ANÁLISE DOS DADOS}

\section{Conhecendo os Dados}

Consideraremos apenas os candidatos a prefeito com valores válidos para todas as variáveis usadas no modelo explicativo. Com isso, haverá uma redução no número total de concorrentes, assim como no número de municípios por grupo de tamanho ${ }^{17}$. Na Tabela 2 combinamos a classificação por presença de propaganda política gratuita em rádio e/ ou TV (grupo 1 a 3) com as outras, diferenciando o tamanho dos municípios. Essa combinação revela quantos municípios e candidatos se enquadram em cada situação, respectivamente. Nos municípios com até 5 mil eleitores cerca de dois terços não dispõem de acesso nem a rádio, nem a TV, ficando, portanto, sem propaganda política gratuita. Nos municípios entre 5 mil e 10 mil eleitores esta situação se inverte. Somente 35\% não têm acesso ao horário eleitoral. A maioria deles $(65 \%)$ dispõe de acesso à transmissão via rádio. Nos municípios entre 10 mil e 50 mil eleitores este percentual sobe para 84 . Nestes primeiros três grupos há somente alguns casos isolados de municípios com acesso à TV. Nos municípios entre 50 mil e 200 mil eleitores, são poucos os casos em que não há acesso ao horário eleitoral. Dois terços dispõem de estações de rádio e um terço tem transmissão de propaganda eleitoral por TV. Nos municípios acima de 200 mil eleitores, em apenas 83 prevalecem os casos com acesso a propaganda por TV $(70 \%)$.

Considerando a distribuição dos municípios nos grupos de tamanhos, a Tabela 3 apresenta as estatísticas descritivas para as principais variáveis analisadas aqui, separadas por tipo de município e situação do candidato (se eleito ou derrotado). O objetivo é identificar diferenças nas relações entre i) votos obtidos em 2008; ii) tempo de rádio e televisão; iii) gastos efetivos em reais; e iv) total de votos obtidos no primeiro 
Tabela 2

Tamanho e Presença de Propaganda Política (\% de Candidatos)

\begin{tabular}{l|r|r|r|r}
\hline & \multirow{2}{*}{\begin{tabular}{c} 
Total \\
Candidatos \\
\cline { 3 - 4 }
\end{tabular}} & Grupo A & Grupo B & \multicolumn{1}{c}{ Grupo C } \\
\cline { 3 - 4 } & (N) & Sem HGPE & $\begin{array}{c}\text { Só com } \\
\text { HGPE Rádio }\end{array}$ & $\begin{array}{c}\text { Com HGPE } \\
\text { Rádio e TV }\end{array}$ \\
\hline Até 5 mil eleitores & 3.191 & $63 \%$ & $37 \%$ & $0 \%$ \\
5 -10 mil eleitores & 3.190 & $35 \%$ & $65 \%$ & $0 \%$ \\
$10-50$ mil eleitores & 5.047 & $15 \%$ & $83 \%$ & $2 \%$ \\
$50-200$ mil eleitores & 1.137 & $5 \%$ & $61 \%$ & $33 \%$ \\
Acima de 200 mil eleitores & 473 & $0 \%$ & $0 \%$ & $100 \%$ \\
Todos os municípios & 13.038 & $30 \%$ & $63 \%$ & $7 \%$ \\
\hline
\end{tabular}

Fonte: Elaboração própria a partir de análise de dados do TSE.

* O número total é inferior a número de municípios existentes em 2012 em função de falta de dados para algumas variáveis.

Tabela 3

Estatísticas Descritivas (N) e Medianas de \% por Tipo de Município

\begin{tabular}{|c|c|c|c|c|c|c|}
\hline Tamanho & Resultado & $\begin{array}{c}\text { Votos } 1^{\circ} \\
\text { Turno } \\
2008(\%)^{*}\end{array}$ & $\begin{array}{c}\text { Despesa } \\
\text { Efetiva } \\
2012(\%)\end{array}$ & $\begin{array}{c}\text { HGPE } \\
\text { Rádio } \\
2012(\%)^{* *}\end{array}$ & $\begin{array}{c}\text { HGPE } \\
\text { TV } \\
2012(\%)^{* *}\end{array}$ & $\begin{array}{c}\text { Votos } 1^{\mathrm{o}} \\
\text { Turno } \\
2012(\%)\end{array}$ \\
\hline \multirow{3}{*}{$\begin{array}{l}\text { Até } 5 \text { mil } \\
\text { eleitores }\end{array}$} & Derrotado & 38,31 & 33,15 & 0,00 & 0,00 & 41,23 \\
\hline & Eleito & 55,09 & 56,77 & 0,00 & 0,00 & 54,42 \\
\hline & Diff. & 16,78 & 23,62 & 0,00 & 0,00 & 13,19 \\
\hline \multirow{3}{*}{$\begin{array}{l}\text { De } 5 \text { a } 10 \mathrm{mil} \\
\text { eleitores }\end{array}$} & Derrotado & 33,43 & 27,69 & 19,05 & 0,00 & 37,64 \\
\hline & Eleito & 53,39 & 55,37 & 34,27 & 0,00 & 53,74 \\
\hline & Diff. & 19,96 & 27,69 & 15,23 & 0,00 & 16,11 \\
\hline \multirow{3}{*}{$\begin{array}{l}\text { De } 10 \text { a } 50 \\
\text { mil eleitores }\end{array}$} & Derrotado & 25,05 & 20,43 & 23,82 & 0,00 & 30,82 \\
\hline & Eleito & 53,14 & 54,63 & 39,16 & 0,00 & 53,56 \\
\hline & Diff. & 28,10 & 34,20 & 15,34 & 0,00 & 22,74 \\
\hline \multirow{3}{*}{$\begin{array}{l}\text { De } 50 \text { a } 200 \\
\text { mil eleitores }\end{array}$} & Derrotado & 11,82 & 12,94 & 20,97 & 0,00 & 19,72 \\
\hline & Eleito & 52,93 & 52,75 & 39,05 & 0,00 & 53,32 \\
\hline & Diff. & 41,11 & 39,81 & 18,08 & 0,00 & 33,60 \\
\hline \multirow{3}{*}{$\begin{array}{l}\text { Acima de } 200 \\
\text { mil eleitores }\end{array}$} & Derrotado & 1,99 & 1,72 & 8,46 & 8,46 & 4,32 \\
\hline & Eleito & 50,43 & 32,26 & 30,12 & 30,12 & 48,91 \\
\hline & Diff. & 48,44 & 30,54 & 21,66 & 21,66 & 44,59 \\
\hline
\end{tabular}

Fonte: Elaboração própria a partir de análise de dados do TSE.

* As medianas das votações de 2008 levam em consideração os totais de votos obtidos pelos candidatos naquele ano. Assim, é possível comparar os resultados diretamente com os resultados de 2012. Nos testes a seguir serão usados como "memória eleitoral" apenas os percentuais de votos dos partidos com candidatos em 2012 que compunham as coligações em 2008.

** Nos grupos onde há mais de $50 \%$ dos casos com tempo igual a $0 \%$, a mediana assume o valor zero. 
turno de 2012. Todas as medianas são dos percentuais dos valores originais, dado que, em função da grande variabilidade entre os municípios, não se recomenda o uso de média como medida de tendência central neste caso.

A tabela também inclui uma linha que indica as diferenças de valores entre os eleitos e derrotados em cada uma das categorias de municípios. O objetivo é verificar se existem diferenças entre as duas categorias de candidatos em cada grupo de municípios e diferenças dentro dos grupos. A linha (Diff.) ao final do conjunto de dados dos grupos de municípios indica essa diferença do valor da variável entre candidatos eleitos e derrotados em 2012.

Em relação às variáveis de "memória eleitoral", o número de votos obtidos pelos candidatos em 2008 tem impacto positivo para a eleição dos prefeitos. Em todas as categorias de municípios as diferenças são negativas para os derrotados. As diferenças crescem conforme aumenta o tamanho do município, o que significa que em municípios menores os candidatos derrotados tendem a apresentar desempenhos eleitorais mais próximos dos eleitos. Isso vale para todas as cinco categorias de municípios e para as duas disputas analisadas aqui (2008 e 2012). Ou seja, podemos apresentar como hipótese que nos municípios pequenos e médios a importância da votação no passado para o modelo explicativo do sucesso eleitoral no presente é maior, devido à menor diferença entre eleitos e derrotados.

As medianas de recursos financeiros das campanhas apresentaram grandes diferenças entre derrotados e eleitos em todos os grupos de municípios. Essas diferenças são crescentes entre os municípios até 200 mil eleitores, passando de 23,6 pontos percentuais, no primeiro grupo, até 39,8 pontos percentuais no quarto grupo. Porém, quando chegamos ao grupo dos maiores municípios, as diferenças de medianas caem para 30,5 pontos percentuais entre derrotados e eleitos. Isso significa que em municípios com segundo turno os recursos financeiros são distribuídos de maneira mais equitativa entre eleitos e não eleitos.

O horário eleitoral no rádio apresenta diferenças favoráveis aos eleitos em todas as categorias. Candidatos eleitos tendem a dispor de mais tempo em rádio. Aqui também as diferenças são maiores nos municípios acima de 50 mil eleitores. Quanto maior o município, maior a diferença de tempo em rádio a favor dos candidatos eleitos, passando de 15 
pontos percentuais nos municípios entre 5 e 50 mil habitantes para 21 nos municípios maiores.

Quanto ao horário eleitoral na televisão, nos municípios até 200 mil eleitores as medianas foram zero para candidatos eleitos e derrotados, dado que não existem emissoras de TV em número superior a 50\% do total de municípios de cada grupo. Só nos municípios com segundo turno essa variável mostrou diferenças entre eleitos e não eleitos, com 21,6 pontos percentuais a mais de tempo em favor dos eleitos. Quer dizer, quem teve mais tempo em TV tendeu a ser eleito.

A última variável da Tabela 3 mostra que o comportamento das diferenças do número de votos obtidos entre eleitos e derrotados segue o mesmo padrão em 2012. Como esperado, os eleitos têm mais votos que os derrotados e essas diferenças aumentam conforme cresce o tamanho do município, chegando a 44,5 pontos percentuais para os derrotados em relação aos eleitos, na mediana no grupo dos maiores municípios.

As descrições feitas até aqui indicam uma possível relação causal conjunta entre votação no passado, recursos financeiros e horário eleitoral (principalmente no rádio) para explicar o sucesso eleitoral de candidatos às prefeituras brasileiras em 2012. A questão é se essa relação causal é ou não homogênea em municípios de diferentes tamanhos. Elas também indicam comportamentos distintos das variáveis explicativas entre os grupos de municípios. A princípio, podemos afirmar que recursos financeiros e horário gratuito de propaganda eleitoral parecem apresentar relações inversas. Conforme cresce o tamanho do município, diminui a importância dos recursos financeiros e aumenta a dos recursos partidários para a obtenção de votos.

\section{Explicando o Desempenho Eleitoral com Regressão Linear Multivariada}

Em função desses achados, aqui apresentamos o modelo multivariado de análise considerando o efeito das principais variáveis analisadas: (1) recursos financeiros para as campanhas (gastos efetivos pelos candidatos a prefeito); (2) recursos de mídia (tempo de horário eleitoral em rádio e televisão) e (3) recurso de memória eleitoral em termos de votos (votos obtidos pelo partido/coligação do candidato na disputa de 2008). Também levamos em conta (4) a competitividade das eleições e (5) o tamanho dos municípios. No Modelo 1 trabalhamos apenas com o efeito aditivo dessas variáveis. Para verificar como se dá o efeito con- 
junto dessas variáveis no desempenho eleitoral dos candidatos em diferentes tipos de municípios, inserimos no Modelo 2 efeitos de interação do tamanho dos municípios com as primeiras três variáveis.

O resultado da regressão linear multivariada (Tabela 4) permite uma primeira avaliação das nossas hipóteses. No modelo aditivo (Modelo 1) todas as variáveis inseridas têm impacto significativo sobre o resultado eleitoral. Usando o coeficiente Beta padronizado para comparar a contribuição da variância de cada variável sobre os votos obtidos, verificamos que o dinheiro gasto pelos candidatos tem maior peso (beta $0,419)$, em comparação com o tempo de propaganda $(0,106)$ e a memória $(0,230)$. O número de candidatos tem o efeito esperado $(-0,245)$ porque a proporção de votos dos candidatos diminui com a competitividade das eleições. $\mathrm{O}$ tamanho do eleitorado tem efeito significativo, porém de magnitude baixa $(0,041)$. A variação da despesa influencia quatro vezes mais o voto em comparação com o tempo e duas vezes mais que a variação da memória. Este resultado não confirma a nossa expectativa inicial sobre o peso do tempo de propaganda para a decisão do voto. Em comparação com o dinheiro, o tempo de HGPE tem efeito modesto sobre o desempenho eleitoral. Por outro lado, ele informa que a memória eleitoral do partido é um fator importante para explicar o voto. Isto mostra que a nossa variável de controle teve mais importância do que esperávamos inicialmente para a decisão do voto.

Tabela 4

Regressão Multivariada para Explicar o Voto (Beta Padronizado)

\begin{tabular}{l|l|l}
\hline Variável & Modelo 1 & Modelo 2 \\
\hline Dinheiro & $0,419^{* * *}$ & $0,419^{* * *}$ \\
Tempo & $0,106^{* * *}$ & $0,096^{* * *}$ \\
Memória & $0,230^{* * *}$ & $0,221^{* * *}$ \\
Dinheiro x Eleitores & & $-0,024^{*}$ \\
Tempo x Eleitores & & $0,049^{* * *}$ \\
Memória x Eleitores & & $0,038^{* * *}$ \\
Competitividade & $-0,245^{* * *}$ & $-0,252^{* * *}$ \\
N. Eleitores & $0,041^{* * *}$ & 0,008 \\
R2 Ajustado & 0,539 & 0,541 \\
\hline
\end{tabular}

Fonte: Elaboração própria a partir da comparação dos modelos de análise. ${ }^{*}(\mathrm{p}<0,1) ;{ }^{* *}(\mathrm{p}<0,01)$.

O segundo modelo inclui termos de interação da magnitude dos municípios com as variáveis independentes. Queremos saber se o peso de 
cada variável no modelo varia em função do tamanho do eleitorado. Todas as interações se mostram significativas (pelo menos no nível de $\mathrm{p}=0,1)$, porém, com sinais diferentes. Enquanto a influência da memória e do tempo sobre o voto cresce com o tamanho dos municípios, a relação entre despesa e votos diminui. Com estes resultados, temos uma primeira confirmação da nossa hipótese em relação ao efeito moderador do tamanho dos municípios sobre a influência do dinheiro, tempo e memória sobre o voto. Porém, a direção da moderação não se deu na direção esperada em relação ao dinheiro. Quanto maior o município, menor a eficiência do dinheiro em angariar votos. Por outro lado, nos municípios maiores o tempo de propaganda e a memória eleitoral têm um impacto maior sobre o desempenho eleitoral. Para avaliar a nossa segunda hipótese sobre os mecanismos causais que estão por trás dessas interações recorremos à análise de trajetória.

\section{Detalhando Mecanismos Causais do Desempenho Eleitoral com Análise de Trajetória}

A análise de trajetória é uma técnica que utiliza o conceito de variável mediadora em uma regressão, inserindo-a em um teste de regressão para verificar a força da relação anterior das variáveis ${ }^{18}$. Em uma regressão convencional, a variável explicativa é representada pela letra X e a dependente pela letra Y. Aqui, a variável mediadora é representada pela letra M. A mediação ocorre com a inclusão dessa terceira variável na relação, sendo considerada um mecanismo de efeito, importante para quando se quer compreender como uma variável mediadora (M) intermedeia a relação entre $\mathrm{X}$ e $\mathrm{Y}$.

Se X e $Y$ estão correlacionadas, podemos usar um teste de regressão para predizer o valor de $Y$ a partir de X. Também é possível acontecer de X e Y estarem correlacionados devido à mediação da variável $M$. Então, a variável mediadora gera um efeito porque ela encontra-se entre a variável $\mathrm{X}$ e a $\mathrm{Y}(\mathrm{X} \rightarrow \mathrm{M} \rightarrow \mathrm{Y})$. A questão a ser verificada aqui é se o coeficiente Beta da regressão original continua sendo significativo após o efeito de mediação. Se o coeficiente (B) original for reduzido após a inserção da variável mediadora é sinal de que houve um efeito de mediação. Se o Beta continuar o mesmo, significa que M não exerce efeito de mediação. Espera-se que todo mediador M tenha algum efeito sobre a relação entre X e Y. Se houver mudança, então diz-se que existe uma mediação parcial. Se a mudança for completa, fala-se em mediação total. Assim, a análise de trajetória é um tipo de teste para ve- 
rificar o efeito de mediação. Trata-se de uma técnica especial que parte dos modelos de regressão linear múltipla para identificar os pesos individuais das explicações de cada variável independente sobre a variável dependente a partir da mediação de uma ou algumas delas. Ao realizar testes empíricos, a técnica permite uma aproximação entre o modelo teórico - a partir de representações gráficas - e os coeficientes empíricos. Essa técnica usa ilustrações que indicam os componentes de trajetória:

- Retângulos: indicam as variáveis observadas (X, M, Y);

- Círculos: indicam as variáveis não observadas, ou seja, os fatores de erro (e);

- Triângulos: indicam as constantes, ou seja, aquelas características que não variam no modelo;

- Flechas: indicam as direções das associações.

O modelo ilustrativo é representado na Figura 1 a seguir:

Além do efeito direto de $X$ sobre $Y$, há também um efeito mediado de $X$ passando por M para chegar até Y. Em um modelo como o representado acima é possível medir o "tamanho" desse efeito e estabelecer se a variável M apresenta um efeito forte de mediação sobre X e Y. Aqui, a direção da flecha indica a direção da influência. Nesse caso, $X$ influencia $Y$ diretamente e, também, através de $M$. Na Figura 1, $X$ apresenta efeito parcial direto em $\mathrm{Y}$ e um efeito predito até $\mathrm{Y}$ a partir de $\mathrm{M}$. Os efeitos são:

Figura 1

Modelo para Análise de Trajetória

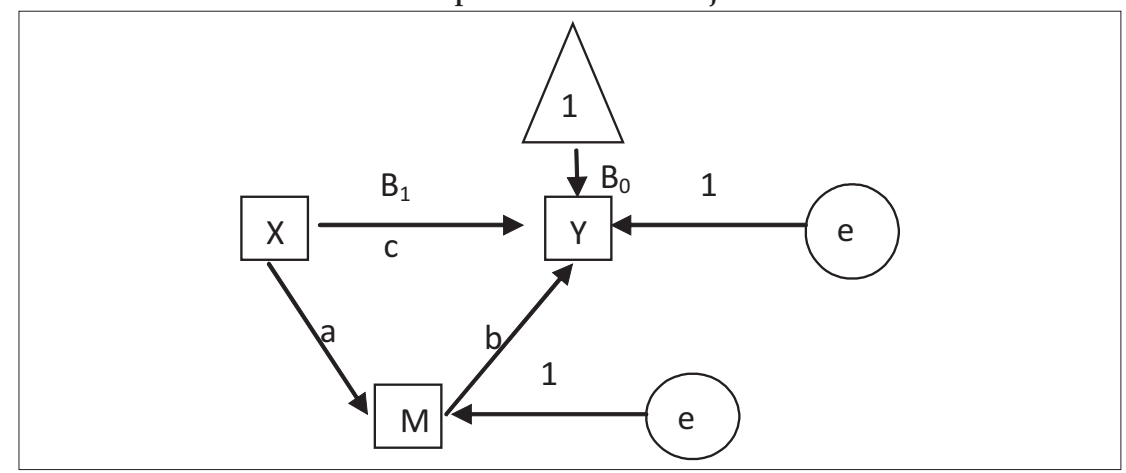

Fonte: Elaboração própria com base nos mecanismos causais de desempenho eleitoral. 
a: trajetória de X para $\mathrm{M}$.

b: trajetória de M para Y.

c: trajetória direta de X para Y (desconsiderando o efeito de M).

Note que se multiplicarmos $\mathrm{a}^{*} \mathrm{~b}$ temos o coeficiente de trajetória indireta de $\mathrm{X}$ sobre $\mathrm{Y}$ passando por $\mathrm{M}$.

Ao aplicar a análise de trajetória para o nosso objeto de pesquisa o primeiro passo é a representação teórica dos efeitos das variáveis no modelo e a interação entre os componentes. Este modelo está representado na Figura 2. Para aplicar a análise de trajetória precisamos desmembrar o modelo em suas várias partes constitutivas. Este desmembramento é realizado na coluna à direita do gráfico. Trata-se de uma regressão (a) com o voto como variável dependente (e as variáveis independentes dinheiro, tempo, memória, competitividade e tamanho); outra regressão (b) com despesas como variável dependente (com as variáveis independentes tempo, memória, competitividade e eleitorado) e uma terceira (c) com tempo como variável dependente (com as variáveis independentes memória e competitividade). Neste sistema de equações se baseia a análise de trajetória a seguir.

Figura 2

Modelo de Trajetória Aplicado às Campanhas para Prefeito em 2012

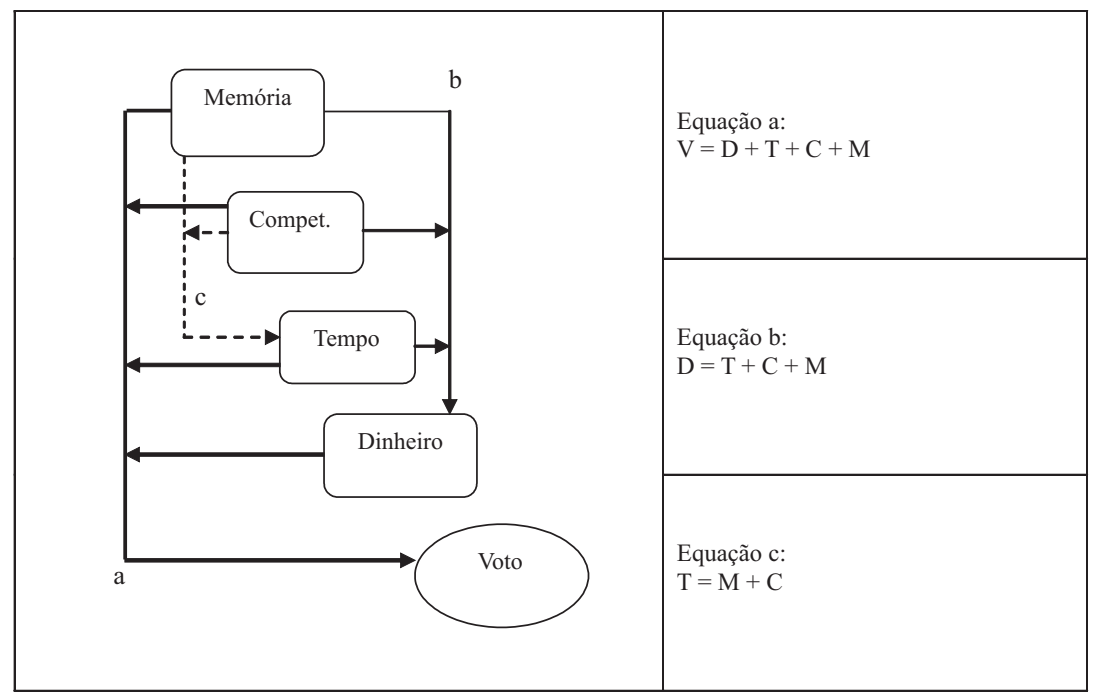

Fonte: Elaboração própria a partir da interação das variáveis eleitorais incidentes sobre o voto.

DADOS - Revista de Ciências Sociais, Rio de Janeiro, vol. 59, no 1, 2016 
Com esses três componentes do sistema de equações que compõem o nosso modelo, podemos reavaliar a contribuição de cada variável para explicar o voto em 2012. Assim, além do efeito direto da votação em 2008 (memória) teremos o efeito indireto da memória sobre o voto por mediação das despesas (Equação b) e também por mediação do tempo (Equação c). Da mesma forma, podemos reavaliar a contribuição de cada fator através das suas contribuições mediadas para o voto e 2012. A Tabela 5 sumariza os principais coeficientes dos modelos aplicados ao conjunto de 4,9 mil municípios estudados aqui. Percebe-se que, embora as três equações apresentem resultados estatisticamente significativos (estatística F alta e com significância abaixo do limite crítico em todos os casos), a primeira equação apresenta um coeficiente de determinação maior. O erro bruto (e), por consequência, é o menor de todos. Esses resultados nos mostram que as equações são robustas, embora não fossem recomendados para predição, dados os elevados erros brutos ${ }^{19}$. O próximo passo é reunir os coeficientes Beta padronizados individuais das variáveis envolvidas em todas as equações. A partir da Figura 3 podemos identificar o conjunto de efeitos diretos e indiretos que as variáveis têm sobre o voto.

Tabela 5

Coeficientes para os Modelos da Análise de Trajetória Considerando todos os Municípios

\begin{tabular}{l|c|c|c}
\hline Equação & $\mathbf{F}$ (sig.) & $\mathbf{r}^{2}$ & $\mathbf{e}$ \\
\hline a & $3.784,60(0,000)$ & 0,537 & 0,680 \\
b & $1.203,65(0,000)$ & 0,217 & 0,885 \\
c & $593,37(0,000)$ & 0,083 & 0,958 \\
\hline
\end{tabular}

Fonte: Elaboração própria a partir de análise de dados do TSE.

No modelo para o conjunto dos mais de 13 mil candidatos, todas as relações são estatisticamente significativas. Mas elas variam em relação à magnitude do impacto nas respectivas equações. As diferenças em relação ao peso de cada variável no sistema de equações estão informadas na Figura 3, que inclui os valores Beta padronizados de cada variável em cada uma das equações, permitindo avaliar o peso relativo de cada fator no conjunto das equações.

A Equação (a) avalia os efeitos diretos das variáveis sobre o voto. Aqui temos novamente os efeitos do Modelo 1 da regressão multivariada 
acima. O dinheiro exerce o efeito mais forte $(0,420)$, seguido de memória $(0,234)$ e tempo de propaganda $(0,106)$. A competitividade, que é avaliada a partir do número de candidatos concorrendo no pleito, tem um efeito mecânico sobre os votos alcançados: quanto mais candidatos, menor a porcentagem média alcançada por candidato $(-0,226)$.

A Equação (b) capta o efeito do tempo e da memória sobre o dinheiro. Aqui avaliamos em que medida os recursos mobilizados na campanha dependem do sucesso no passado e do horário eleitoral. O efeito mais importante vem da memória eleitoral $(0,282)$ que sinaliza aos doadores se o candidato tem chance de entrar como concorrente sério na disputa. O efeito do tempo de propaganda é menor $(0,137)$. Novamente o número de candidatos influencia negativamente a porcentagem de recursos arrecadados $(-0,190)$, pelo efeito mecânico da divisão das porcentagens.

A Equação (c) capta o efeito da memória e da competitividade sobre o tempo. Aqui medimos quanto o resultado eleitoral passado do partido influencia a distribuição do tempo na próxima eleição. Sabemos que esta relação é mediada por efeitos políticos e institucionais da eleição nacional intermediária. $\mathrm{O}$ baixo coeficiente referente à memória $(0,215)$ mostra que há um distanciamento grande entre o desempenho eleitoral passado no município e o tempo de HGPE calculado a partir de um quociente nacional para a eleição. Mesmo que um partido tenha tido um excelente desempenho no último pleito municipal, a atribuição de tempo na próxima eleição refletirá este desempenho de forma bastante imprecisa, como indica o coeficiente Beta baixo para esta relação. Novamente o número de candidatos influencia negativamente a distribuição do tempo $(-0,116)$. Este é o efeito direto da regra da Justiça Eleitoral que distribui o tempo total de propaganda entre os partidos apresentando candidatos, regra que resulta em parcelas maiores em pleitos pouco disputados.

A partir dos coeficientes na Figura 3 é possível reavaliar os efeitos da competitividade, da memória, do tempo e do dinheiro sobre o voto. Além do efeito direto, representado na Equação (a), tempo, memória e competitividade têm efeitos indiretos sobre o voto. Assim, pela Equação (b), tempo, memória e competitividade têm efeito indireto pela mediação do dinheiro. A partir da Equação (c), memória e competitividade influenciam o voto por meio da sua influência sobre o tempo. $\mathrm{O}$ 
Figura 3

Coeficientes para os Três Modelos

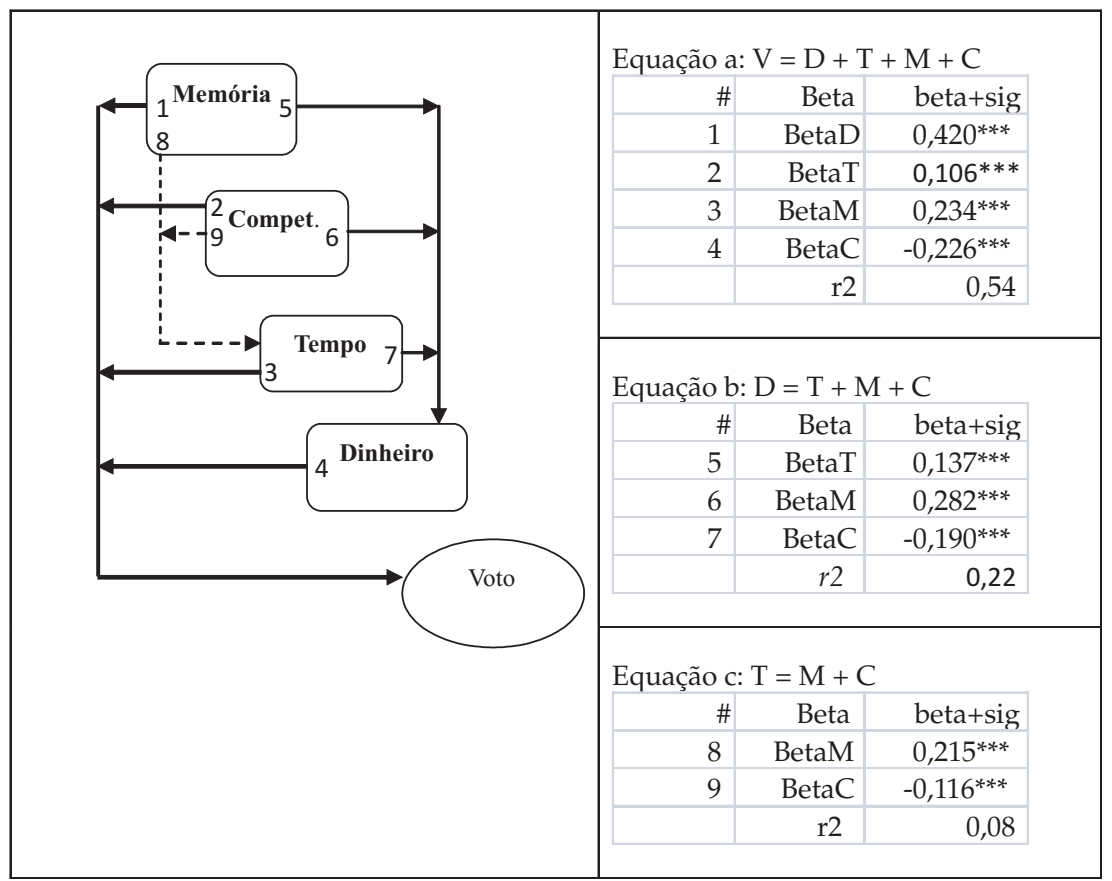

Fonte: Elaboração própria a partir a inclusão do coeficiente Beta padronizado.

conjunto desses efeitos mediados sobre o voto permite uma reavaliação da importância do dinheiro, do tempo e da memória sobre o voto ${ }^{20}$. A Tabela 6 informa o resultado da reavaliação do peso explicativo das três variáveis. Somando os efeitos diretos com os efeitos indiretos chegamos ao cálculo do efeito total de cada variável.

Tanto a variável tempo de HGPE quanto a variável memória aumentam consideravelmente o seu valor explicativo sobre os votos quando levamos em consideração estes efeitos indiretos. Comparando os efeitos diretos com os efeitos totais podemos tirar duas conclusões: (1) a ordem de importância das variáveis dinheiro, tempo e memória não mudou; (2) a distância entre as variáveis diminuiu. Principalmente a memória eleitoral ficou próxima do peso dos recursos financeiros. $\mathrm{O}$ peso do tempo em rádio e televisão ainda é bastante reduzido. A Tabela 6 nos permite identificar os efeitos totais de cada variável para a obtenção de votos em 2012. 
Tabela 6

Efeitos Sumarizados para Desempenho Eleitoral em 2012 Considerando todos os Municípios

\begin{tabular}{l|c|c|c}
\hline Variável & Efeito Direto & Efeito Indireto* $^{*}$ & Efeito Total \\
\hline Dinheiro & 0,420 & - & 0,420 \\
Tempo HGPE & 0,106 & 0,058 & 0,164 \\
Memória & 0,234 & 0,141 & 0,375 \\
\hline
\end{tabular}

Fonte: Elaboração própria a partir de análise de dados do TSE.

* É a soma das multiplicações de todas as trajetórias individuais da variável.

O resultado da análise de trajetória nos ajuda a entender melhor os mecanismos causais que estão por trás da relação causal entre recursos tempo, memória, competitividade e voto. A partir do modelo das relações causais que subjaz a análise, podemos reavaliar que o efeito indireto da memória sobre o voto é ainda maior do que inicialmente avaliado na regressão linear. Percebe-se que, ao considerarmos todos os candidatos, independente do tamanho do município, os recursos financeiros apresentam o maior efeito total sobre a variação de votos em $2012(0,420)$, seguidos da memória eleitoral, com coeficiente de 0,375 para votação em 2008 e horário eleitoral com apenas 0,164.

\section{Reavaliando a Tese sobre o Efeito Moderador por Tamanho do Município}

No entanto, esses resultados gerais não são suficientes para indicar as particularidades das disputas eleitorais em função do tamanho do município. O modelo de regressão com os termos interativos sugeriu que a relação entre as variáveis independentes e o voto poderia ser moderada pelo tamanho dos municípios. Usaremos novamente a análise de trajetória para avaliar mais de perto o efeito moderador do tamanho dos municípios sobre a dinâmica do voto. Replicamos os modelos para cada um dos cinco grupos de municípios apresentados anteriormente para identificar as variações de efeitos das variáveis explicativas e mediadores sobre o desempenho dos candidatos em contextos municipais distintos de campanha. Os resultados desta avaliação dos municípios separados por tamanho estão na Figura 4.

A comparação entre os grupos permite identificar diferenças importantes. Na primeira equação vemos que o peso direto do dinheiro sobre a votação (linha 1) cresce com o tamanho do município, com exceção dos municípios acima de 200 mil eleitores, onde ele cai abruptamente. 
Figura 4

Coeficientes Parciais por Tamanho de Município

\begin{tabular}{|c|c|c|c|c|c|c|}
\hline \multicolumn{7}{|c|}{ Equação a: $V=D+T+M+C$} \\
\hline & & até 5 mil & 5-10 mil & $10-50$ mil & \multicolumn{2}{|c|}{$50-200 \mathrm{mil}>200 \mathrm{mil}$} \\
\hline 1 & BetaD & $0,355^{* * *}$ & $0,386^{* * *}$ & $0,426^{* * *}$ & $0,466^{* * *}$ & $0,236^{* * *}$ \\
\hline 2 & BetaT & $0,046^{* * *}$ & $0,069^{* * *}$ & $0,165^{* * *}$ & $0,284^{* * *}$ & $0,579 * * *$ \\
\hline 3 & BetaM & $0,200^{* * *}$ & $0,222^{* * *}$ & $0,211^{* * *}$ & $0,145^{* * *}$ & $0,077^{* *}$ \\
\hline \multirow[t]{2}{*}{4} & BetaC & $-0,327^{* * *}$ & $-0,265^{* * * *}$ & $-0,151^{* * *}$ & $-0,060^{* * *}$ & $-0,021$ \\
\hline & \multicolumn{2}{|l|}{ r2 } & 0,48 & 0,53 & 0,66 & 0,67 \\
\hline \multicolumn{7}{|c|}{ Equação b: $D=T+M+C$} \\
\hline & & até 5 mil & 5-10 mil & $10-50$ mil & \multicolumn{2}{|c|}{$50-200 \mathrm{mil}>200 \mathrm{mil}$} \\
\hline 5 & BetaT & $0,042^{* *}$ & $0,096^{* * *}$ & $0,229^{* * *}$ & $0,452^{* * *}$ & $0,705^{* * *}$ \\
\hline 6 & BetaM & $0,229 * * *$ & $0,226^{* * * *}$ & $0,243^{* * *}$ & $0,241^{* * *}$ & $-0,057$ \\
\hline \multirow[t]{2}{*}{7} & BetaC & $-0,202^{* * *}$ & $-0,198^{* * *}$ & $-0,117^{* * *}$ & 0,000 & $-0,032$ \\
\hline & \multicolumn{2}{|l|}{ r2 } & 0,16 & 0,23 & 0,41 & 0,45 \\
\hline \multicolumn{7}{|c|}{ Equação c: $T=M+C$} \\
\hline & & até 5 mil & 5-10 mil & $10-50 \mathrm{mil}$ & \multicolumn{2}{|c|}{$50-200 \mathrm{mil}>200 \mathrm{mil}$} \\
\hline 8 & BetaM & $0,080^{* * *}$ & $0,195^{* * *}$ & $0,349^{* * *}$ & $0,616^{* * *}$ & $0,678^{* * *}$ \\
\hline \multirow[t]{2}{*}{9} & BetaC & $-0,082^{* * *}$ & $-0,178^{* * *}$ & $-0,265^{* * *}$ & $-0,182^{* * *}$ & $-0,096^{* * *}$ \\
\hline & r2 & 0,02 & 0,10 & 0,28 & 0,51 & 0,51 \\
\hline
\end{tabular}

Fonte: Elaboração própria a partir de análise de dados do TSE.

A trajetória do tempo de propaganda (linha 2) é diferente. Ele cresce de forma mais acentuada com o tamanho dos municípios, com um salto significativo na última categoria. Nos municípios acima de $200 \mathrm{mil}$ eleitores o tempo se torna o fator direto mais importante para o desempenho eleitoral. A memória eleitoral tem um efeito mais forte sobre o voto nos municípios menores, com uma queda grande nos municípios acima de 200 mil habitantes (linha 3). Este resultado retrata de forma mais detalhada os efeitos interativos (negativo no caso das despesas e positivo no caso do tempo) com o tamanho do eleitorado nos modelos de regressão da população total. Por outro lado, verificamos que o efeito não é linear no primeiro caso, o que pode ser responsável pela significância baixa desta interação na regressão linear com interações (Modelo 2 da Tabela 4).

Em relação aos efeitos indiretos observamos igualmente diferenças importantes. Na medida em que o tamanho dos municípios aumenta, o horário eleitoral exerce uma influência mais forte sobre o dinheiro arrecadado (linha 5). Este aumento é o mais acentuado comparando to- 
das as séries de coeficientes. A memória eleitoral (linha 6) tem efeito menor e se mantém em patamar constante entre os municípios até 200 mil habitantes, mas seu coeficiente é mais baixo na última categoria. $\mathrm{Na}$ terceira equação verificamos que o desempenho eleitoral na última eleição (linha 8) tem uma relação bastante tênue com a distribuição do tempo, mas estes valores se aproximam na medida em que os municípios crescem. Uma interpretação para esta aproximação é que nos maiores municípios todos os partidos grandes se empenham nas eleições, reproduzindo resultados mais próximos dos nacionais. Não são necessariamente as eleições municipais nesses municípios que influenciam a distribuição do tempo. Ao contrário, as eleições municipais nos grandes municípios se aproximam mais da média do resultado das eleições para a Câmara dos Deputados.

Resta calcular novamente os efeitos indiretos das diferentes variáveis e contrastá-los com os efeitos diretos. A Tabela 7 informa o resultado deste cálculo para os cinco grupos. As colunas da tabela informam os

Tabela 7

Efeitos Sumarizados para Desempenho Eleitoral em 2012 por

Tamanho do Município

\begin{tabular}{|c|c|c|c|c|c|c|}
\hline Tamanho & Variável & $\begin{array}{l}\text { Efeito } \\
\text { Direto }\end{array}$ & $\begin{array}{c}\text { Efeito } \\
\text { Indireto* }\end{array}$ & $\begin{array}{l}\text { Efeito Indireto/ } \\
\text { Efeito Direto }\end{array}$ & $\begin{array}{c}\text { Efeito } \\
\text { Total }\end{array}$ & $\begin{array}{c}\text { Posição no } \\
\text { Grupo }\end{array}$ \\
\hline \multirow{3}{*}{$\begin{array}{l}\text { Grupo } 1 \\
\text { (até } 5 \text { mil } \\
\text { eleitores) }\end{array}$} & Despesa & 0,355 & - & - & 0,355 & 1 \\
\hline & Tempo & 0,046 & 0,015 & $33 \%$ & 0,061 & 3 \\
\hline & Memória & 0,200 & 0,085 & $43 \%$ & 0,285 & 2 \\
\hline \multirow{3}{*}{$\begin{array}{l}\text { Grupo } 2 \\
\text { (5-10 mil } \\
\text { eleitores) }\end{array}$} & Despesa & 0,386 & - & - & 0,386 & 1 \\
\hline & Tempo & 0,069 & 0,037 & $54 \%$ & 0,106 & 3 \\
\hline & Memória & 0,222 & 0,100 & $45 \%$ & 0,323 & 2 \\
\hline \multirow{3}{*}{$\begin{array}{l}\text { Grupo } 3 \\
\text { (10-50 mil } \\
\text { eleitores) }\end{array}$} & Despesa & 0,426 & - & - & 0,426 & 1 \\
\hline & Tempo & 0,165 & 0,098 & $59 \%$ & 0,263 & 3 \\
\hline & Memória & 0,211 & 0,161 & $76 \%$ & 0,372 & 2 \\
\hline \multirow{3}{*}{$\begin{array}{l}\text { Grupo } 4 \\
\text { (50-200 mil } \\
\text { eleitores) }\end{array}$} & Despesa & 0,466 & - & - & 0,466 & 2 \\
\hline & Tempo & 0,284 & 0,210 & $74 \%$ & 0,495 & 1 \\
\hline & Memória & 0,145 & 0,287 & $198 \%$ & 0,432 & 3 \\
\hline \multirow{3}{*}{$\begin{array}{l}\text { Grupo } 5 \\
\text { (acima de } 200 \\
\text { mil eleitores) }\end{array}$} & Despesa & 0,236 & - & - & 0,236 & 3 \\
\hline & Tempo & 0,579 & 0,166 & $29 \%$ & 0,746 & 1 \\
\hline & Memória & 0,077 & 0,379 & $492 \%$ & 0,456 & 2 \\
\hline
\end{tabular}

Fonte: Elaboração própria a partir de análise de dados do TSE.

* É a soma das multiplicações de todas as trajetórias individuais da variável. 
efeitos diretos, indiretos, a relação entre estes dois (coluna com porcentagens), o efeito somado dos dois e a importância relativa de cada variável dentro de cada grupo (última coluna).

Comparando os grupos de municípios de diferentes tamanhos, constatamos diferenças marcantes em relação aos efeitos indiretos e totais das variáveis tempo e memória. Em relação ao tempo, o peso dos efeitos indiretos cresce com o tamanho dos municípios, de 33\% (Grupo 1) para $74 \%$ (Grupo 4$)^{21}$. Somente no Grupo 5 este incremento se reduz ao patamar inicial (29\%). No cômputo total a variável tempo fica em terceiro lugar nos primeiros três grupos, passando para o primeiro nos Grupos 4 e 5. Em relação à variável memória o impacto indireto cresce de forma mais acentuada e ultrapassa, nos Grupos 4 e 5, o peso dos efeitos diretos (198\% e $492 \%$, respectivamente). Mesmo assim, a posição relativa da memória fica em segundo lugar e cai para o terceiro no Grupo 4. Como resultado destas alterações em relação às variáveis tempo e memória, o peso da variável despesa (que não tem efeitos indiretos sobre o voto) diminui relativamente a outros fatores. No cômputo da importância relativa, a variável perde o seu peso preponderante (nos Grupos 1-3) para tempo (no Grupo 4) e para tempo e memória (no Grupo 5).

No Grupo 5, que reúne os 83 maiores municípios do país - os que estão acima de 200 mil eleitores - os resultados são bastante distintos dos demais. A começar pelos coeficientes de determinação das equações, que ficam mais próximos uns dos outros e, pela primeira vez, a Equação (c) apresenta um $\mathrm{r}^{2}$ superior ao da Equação (b). Aqui também os efeitos individuais são bem distintos, a começar pelo maior, que é o tempo de HGPE $(0,746)$, seguido da memória $(0,446)$ e, por fim, as receitas em $2012(0,236)$. Isso quer dizer que em grandes municípios, o tempo de rádio e TV importa mais para explicar as variações dos votos do que o resultado da eleição anterior e muito mais do que as receitas de campanha. Por fim, outra diferença importante é que, pela primeira vez, apareceram coeficientes individuais negativos, ou seja, com efeito contrário ao desempenho eleitoral, tal como o impacto negativo da memória eleitoral (linha 6 da Figura 4) ${ }^{22}$. Essas diferenças de explicação para os municípios com mais de 200 mil eleitores em relação aos demais podem estar relacionadas a diferentes fatores. Em campanhas com eventual segundo turno, a arrecadação mais intensiva já no final do primeiro turno pelos candidatos com chance de chegar no segundo turno pode distorcer a relação com as outras variáveis. Também a variação 
maior do tamanho das cidades neste último grupo sugere análises mais detalhadas.

Para isolar mais claramente o fator tamanho dos municípios e aferir o seu impacto sobre a dinâmica da campanha eleitoral, aplicamos a mesma análise de trajetória ao grupo B dos municípios que dispõem do tempo de propaganda no rádio, mas sem TV. Com esta limitação da análise a municípios com o mesmo tipo de acesso ao horário eleitoral gratuito reduzimos a variedade dos fatores independentes, ganhando mais clareza sobre o peso do tempo de propaganda. Resumimos o balanço sobre os efeitos diretos e indiretos do Gráfico 3. Para fins de comparação, reproduzimos os resultados anteriores referentes a todos os municípios no Gráfico 2 a seguir.

Em primeiro lugar, verificamos que não há nenhum município com acesso somente a rádio no último grupo (com mais de 200 mil eleitores). Esta categoria está vazia no Gráfico 2. Em segundo lugar, podemos verificar que as diferenças entre os efeitos das variáveis despesa, tempo e memória nos diferentes grupos de municípios se mantêm e apontam na mesma direção.

\section{Gráfico 2}

O Impacto da Despesa, do Tempo e da Memória sobre o Voto em todos os Municípios

\section{Gráfico 3}

O Impacto da Despesa, do Tempo e da Memória sobre o Voto nos Municípios com HGPE em Rádio Somente

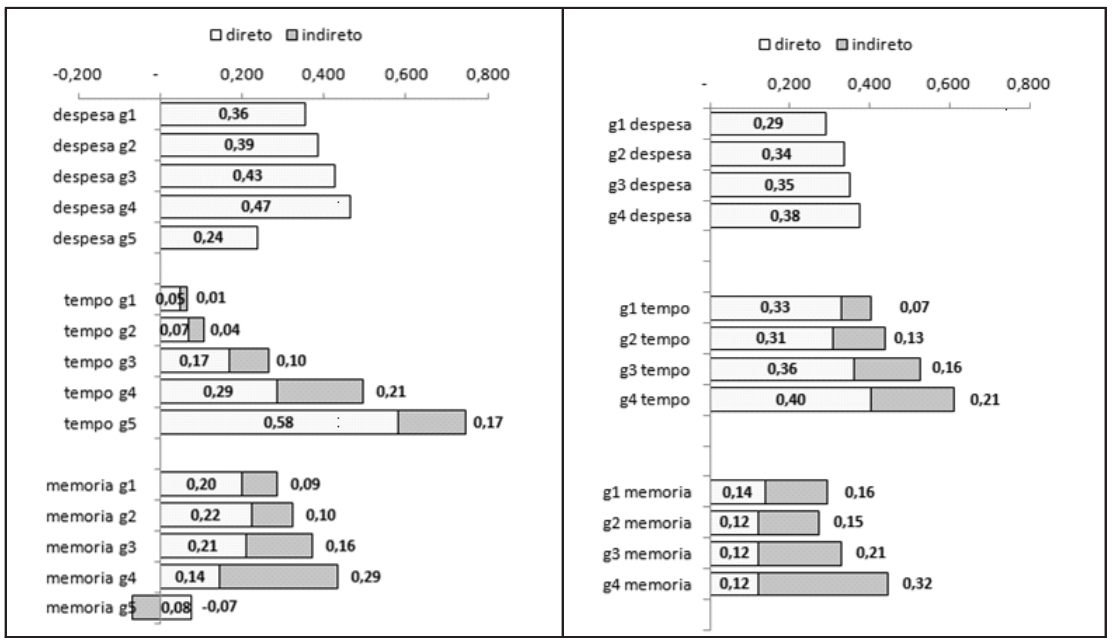

Fonte: Elaboração própria a partir de análise de dados do TSE.

DADOS - Revista de Ciências Sociais, Rio de Janeiro, vol. 59, nº 1, 2016 
A importância das três variáveis cresce com o tamanho dos municípios. Observamos uma distância clara em relação à influência direta do tempo de rádio sobre o voto já nos municípios dos primeiros dois grupos. Em todos os grupos, o tempo de HGPE concorre com as despesas de campanha em importância para o voto, mas a influência direta da memória eleitoral é claramente inferior. Os efeitos indiretos fazem novamente a diferença, lançando tempo de propaganda para o primeiro lugar (em função da sua influência sobre as despesas) e colocando a memória eleitoral no mesmo patamar da receita (em função da sua influência mecânica sobre o tempo e o seu impacto sobre a arrecadação de recursos).

\section{CONCLUSÕES}

Uma primeira conclusão a que podemos chegar diz respeito à impossibilidade de analisar eleições em municípios brasileiros considerando-os como parte de um universo único. Mesmo usando um número restrito de variáveis explicativas e um conjunto homogêneo de fontes de dados, os efeitos sobre a votação municipal variam. As condições de disputa em municípios pequenos são distintas das de municípios grandes e, quando se pretende explicar o desempenho eleitoral dos candidatos, isso deve ser levado em consideração. Neste trabalho fica claro que os recursos financeiros têm um lugar importante na disputa eleitoral, pelo seu efeito direto sobre o desempenho eleitoral, mas este efeito direto é relativamente constante nos municípios até 200 mil eleitores, variando bastante em relação aos maiores. Ou seja, podemos afirmar que não é possível analisar eleições municipais no Brasil como se elas acontecessem em um "grande distritão", desconsiderando as particularidades geradas pelas diferenças no número de eleitores de cada distrito eleitoral e, também, não são adequadas as conclusões a que se chega sobre o que explica o voto em disputas eleitorais se não considerarmos minimamente o contexto político anterior à campanha em análise.

O tempo de HGPE é o fator cujo peso varia de forma mais significativa entre os municípios. Isto ocorre em função de dois mecanismos. Primeiro, o acesso ao horário eleitoral para as campanhas locais em função da infraestrutura municipal e, segundo, em função da influência indireta do tempo de propaganda sobre as despesas dos candidatos. Este efeito indireto cresce nos municípios maiores, possivelmente em 
função de programas mais sofisticados, e eleva o tempo de propaganda ao fator mais importante, influenciando o desempenho eleitoral.

O resultado mais surpreendente diz respeito ao papel da memória eleitoral. O seu efeito direto é modesto e claramente inferior ao papel do dinheiro e do tempo de propaganda. Porém, o efeito indireto é relevante. Isto se deve novamente a dois mecanismos. O primeiro é o efeito da relação entre votação passada e tempo de HGPE no futuro. Vimos que esta relação é mais do que mecânica. Ela inclui a mediação política na eleição intermediária e o efeito padronizador da regra do horário eleitoral. O resultado é que, principalmente nos pequenos municípios, a proporção de votos na última eleição tem uma correlação fraca com o tempo alocado a cada partido na eleição seguinte. Este vínculo indireto da memória via horário eleitoral é fraco. Por outro lado, o vínculo mais forte passa pelos recursos. Os doadores alocam mais recursos em candidatos que têm alguma viabilidade e um dos indicadores fortes é o sucesso eleitoral passado. Mais do que a memória do eleitor, a atuação de candidatos e doadores torna o resultado anterior um importante fator para o desempenho nas eleições seguintes.

Em relação ao modelo analítico da análise de trajetória aqui empregado, o mesmo mostrou-se forte para complementar a regressão linear multivariada. Enquanto esta última apresentou efeitos interativos importantes entre a variável tamanho do município e as demais, a exploração de todas as interações embutidas no modelo analítico proposto não rendeu coeficientes estáveis. Adicionalmente, a saturação da regressão multivariada com muitas interações leva a problemas de interpretação dos respectivos coeficientes. A técnica de análise de trajetória mostrou-se bastante produtiva como complementar a análise multivariada, pois, ao considerar os efeitos indiretos, conseguimos ganhar uma ideia mais clara sobre os mecanismos causais que vinculam memória eleitoral, tempo de propaganda e dinheiro gasto em campanha ao desempenho eleitoral mais recente.

(Recebido para publicação em julho de 2014) (Reapresentado em março de 2015) (Aprovado para publicação em dezembro de 2015) 


\section{Bruno Wilhelm Speck e Emerson Urizzi Cervi}

\section{NOTAS}

1. Utilizamos os dados do Censo Municipal Instituto Brasileiro de Geografia e Estatística (IBGE) de 2006 para os dados sobre a cobertura de TV e os dados da Agência Nacional de Telecomunicações (Anatel) 2013 para a cobertura de rádio.

2. São regulados o período ( 45 dias antes das eleições), os horários de veiculação (vários blocos por dia) e a dedicação dos horários a diferentes cargos (vereador e prefeito, no caso das eleições municipais).

3. A redação da lei em vigor em 2012 definiu que seria usada (dentro das possibilidades técnicas) a presença de canais de TV aberta para alcançar os municípios acima de 200 mil habitantes sem estações próprias.

4. Embora exista a possibilidade de municípios disporem de retransmissão de TV, sem estação própria de rádio, nenhum município se enquadra nesta categoria.

5. Há também trabalhos que tocam indiretamente na questão da relação entre a mídia eletrônica e a política. Boas e Hidalgo (2011) identificam que políticos que vencem eleições têm uma chance maior de ter um pedido de licença para um canal de rádio aprovado pelo Ministério de Comunicações e que políticos que controlam estações de rádio têm uma maior probabilidade de vencer nas próximas eleições.

6. Os missing values criados a partir destes filtros de exclusão se distribuem da seguinte forma sobre o número de municípios: até 5 mil eleitores: 13,3\%, até 10 mil: 12,6\%, até 50 mil: $12,5 \%$, até $200 \mathrm{mil}: 6,4 \%$, acima $200 \mathrm{mil}: 0 \%$. A mesma porcentagem de missing values para a totalidade dos candidatos em cada categoria de municípios é: candidatos em municípios com até 5 mil eleitores: 13,9\%, até 10 mil: 15,9\%, até 50 mil: 17,5\%, até 200 mil: 14,6\%, acima 200 mil: 8,7\%. Devemos lembrar que a maior parte (dois terços) dos missing values para os candidatos se refere ao não deferimento da candidatura pelo TSE.

7. Dados do TSE referentes às eleições municipais de 2008 e 2012 em http:/ / www.tse. jus.br/eleicoes/repositorio-de-dados-eleitorais

8. Somente os recursos declarados nas contas dos "comitês únicos" e pelos "diretórios dos partidos" não entraram na conta porque nestas não é possível separar recursos de vereadores e prefeitos.

9. Dados da pesquisa Perfil dos Municípios Brasileiros. Cultura 2006, disponíveis em: http://www.ibge.gov.br/home/estatistica/economia/perfilmunic/2006/default. shtm

10. Dados da Anatel a respeito das empresas de telecomunicação nos municípios disponíveis em: http:/ / www.anatel.gov.br/Portal/exibirPortalInternet.do

11. A variável a respeito da presença do horário eleitoral próprio na TV foi codificada como binária, identificando a presença ou ausência de transmissão da propaganda dos candidatos locais na TV, uma vez que o tempo disponível é exatamente o mesmo do rádio.

12. Por exemplo: na eleição 2008 apresentaram candidatos os partidos A, B, C e D, este último coligado com $\mathrm{E}$ e F, com as votações de $15 \%, 30 \%, 20 \%$ e $35 \%$, respectivamente. Na eleição 2012 os partidos A, D e F apresentaram candidatos. B apoiou A, C não apresentou candidato nem apoiou outro, E apoiou F. No nosso banco da memória buscamos reconstruir o dado da votação passada dos partidos e respectivos coliga- 
dos que apoiam os três candidatos na eleição 2012, com os seguintes resultados: A $(15 \%+30 \%=45 \%)$, D $(35 \%)$ e $\mathrm{F}(0 \%+0 \%=0 \%)$.

13. Para uma discussão mais detalhada do efeito das regras de alocação do horário eleitoral, ver Speck e Campos (2014).

14. Lei Eleitoral no 9.504, de 30 de setembro de 1997, Art.44 a 58.

15. Ou pelos partidos que integram a coligação eleitoral para eleger o prefeito em 2012.

16. Se todos os partidos apresentassem candidatos em todos os municípios, a distribuição de recursos seria exatamente igual em todas as disputas eleitorais. Porém, há variações em função da ausência de alguns partidos na disputa eleitoral e da formação de coligações para eleição do prefeito. A ausência de um partido da disputa para prefeito resultará na redução do divisor (número de partidos/coligações) para definir a distribuição equitativa de recursos, bem como do divisor (número de deputados na Câmara de Deputados) para definir a distribuição proporcional. A formação de coligações resultará somente na redução do divisor do número de partidos/coligações para a divisão equitativa dos recursos. O cálculo da divisão proporcional continua inalterado.

17. A redução do número de candidatos e municípios se dá em função de quatro filtros. Primeiro, como já mencionamos, apenas as candidaturas deferidas sem ressalvas entraram no banco de dados. Segundo, também excluímos os candidatos para os quais não dispomos de prestações de contas individuais. Há duas possíveis razões para isto: os candidatos podem prestar contas junto com os candidatos à Câmara de Vereadores do mesmo partido, por meio de um comitê único, o que não permite a identificação dos recursos gastos por eles. A segunda possibilidade é que os candidatos podem não ter cumprido a obrigação legal de prestar contas. Terceiro, não entraram no banco de dados municípios criados entre 2008 e 2012, porque nestes casos não foi possível reproduzir os resultados das eleições anteriores. Por último, excluímos candidaturas que aparecem como não competitivas no banco de dados.

18. Referências introdutórias sobre Path Analysis são Holland (1988), Lleras (2005), Kaplan (2009) ou Pestana e Gagueiro (2003:650-652).

19. O que explica a significância dos modelos é o grande número de casos, mais de 13,6 mil candidatos na regressão.

20. Aqui não discutimos em detalhe o efeito mecânico da competitividade por ser de menor interesse analítico.

21. O peso relativo é resultado da divisão dos efeitos indiretos sobre os efeitos diretos. No caso da variável tempo no grupo $1(0,015 / 0,046=) 33 \%$ e no grupo 4 $(0,210 / 0,284=) 75 \%$.

22. O efeito negativo é indireto e resultado da multiplicação do efeito dos votos em 2008 $(-0,057)$ com despesas de campanha em $2012(0,236)$, que resulta em $-0,013$. Os coeficientes negativos em relação à competitividade já eram esperados, como dissemos antes. 


\section{Bruno Wilhelm Speck e Emerson Urizzi Cervi}

\section{REFERÊNCIAS BIBLIOGRÁFICAS}

ALMEIDA, Maria Hermínia Tavares de; CARNEIRO, Leandro Piquet. (2003), “Liderança Local, Democracia e Políticas Públicas no Brasil”. Opinião Pública, vol. IX, no 1, pp. 124-147.

ALMEIDA, Acir; LOPEZ, Felix. (2014), "Representação Política Local e Clientelismo", in M. M. da Rocha; M. T. M. Kerbauy (orgs.), Eleições, Partidos e Representação Política nos Municípios Brasileiros. Juiz de Fora, UFJF Editora, pp. 159-189.

AVELAR, Lúcia; LIMA, Fernão Dias. (2000), “Lentas Mudanças. O Voto e a Política Tradicional. Lua Nova, vol. 49, pp. 195-255.

AVELAR, Lúcia; WALTER, Maria Inez Machado Telles. (2008), “Lentas Mudanças: O Voto e a Política Tradicional. Opinião Pública, vol. 14, no 1, pp. 96-122.

BARRETO, Álvaro A. de B. (2009), “Reeleição de Prefeitos no Brasil do Período de 1996 a 2008". Revista Debates, vol. 3, no 2.

BOAS, Taylor C.; HIDALGO, Daniel. (2011), “Controlling the Airwaves: Incumbency Advantage and Community Radio in Brazil". American Journal of Political Science, vol. 55, no 4, pp. 869-885.

; RICHARDSON, Neal P. (2014), “The Spoils of Victory: Campaign Donation and Government Contracts in Brazil". The Journal of Politics, vol. 76, no 2, pp. 415-429.

BOHN, Simone R.; PAIVA, Denise. (2009), “A Volatilidade Eleitoral nos Estados. Sistema Partidário e Democracia no Brasil". Revista de Sociologia e Política, vol. 17, no 33, pp. 187-208.

BOLOGNESI, Bruno; CERVI, Emerson U. (2011), Distribuição de Recursos e Sucesso Eleitoral nas Eleições de 2006. Trabalho apresentado no 35o Encontro Anual da Anpocs, Caxambu, 24-28 de outubro.

BRAGA, Maria do Socorro Sousa; BOURDOUKAN, Adla. (2009), "Partidos Políticos no Brasil: Organização Partidária, Competição Eleitoral e Financiamento Público". Perspectivas, vol. 35, pp. 117-148.

CARNEIRO, Leandro Piquet; ALMEIDA, Maria Hermínia Tavares de. (2008), “Definindo a Arena Política Local: Sistemas Partidários Municipais na Federação Brasileira". DADOS - Revista de Ciências Sociais, vol. 51, no 2, pp. 403-432.

CERVI, Emerson U. (2010), "Financiamento de Campanha e Desempenho Eleitoral no Brasil: Análise das Contribuições de Pessoas Jurídicas, Físicas e Partidos Políticos às Eleições de 2008 nas Capitais de Estado". Revista Brasileira de Ciência Política, no 4, pp. 135-167.

(2011), “O Uso do HGPE como Recurso Partidário em Eleições Proporcionais no Brasil". Opinião Pública, vol. 17, no 1, pp. 106-136.

CLAESSENS, Stijn; FEIJEN, Erik; LAEVEN, Luc. (2008), "Political Connections and Preferential Access to Finance: The Role of Campaign Contributions". Journal of Financial Economics, vol. 88, no 3, pp. 554-580. 
DANTAS, Humberto. (2012), “O Horário Eleitoral Gratuito na Televisão e o Padrão das Coligações em Eleições Majoritárias Municipais". Leviathan - Cadernos de Pesquisa Política, no 5, pp.1-14.

FIGUEIREDO FILHO, Dalson Britto. (2009), O Elo Corporativo? Grupos de Interesse, Financiamento de Campanha e Regulação Eleitoral. Dissertação (Mestrado em Ciência Política), UFPE, Recife.

FLEISCHER, David. (2002), “As Eleições Municipais no Brasil: Uma Análise Comparativa (1982-2000)”. Opinião Pública, vol. 8, no 1, pp. 80-105.

HEILER, Jeison Giovanni. (2011), Democracia: Jogo das Incertezas x Financiamento de Campanhas. Uma Análise das Prestações de Contas das Campanhas de Vereadores de SC. Dissertação (Mestrado em Sociologia Política), UFSC, Florianópolis.

HOLLAND, Paul W. (1988), “Causal Inference, Path Analysis, and Recursive Structural Equations Models". Sociological Methodology, vol. 18, pp. 449-484.

JARDIM, Márcia. (2004), "Palanque Eletrônico em Eleições Locais: Aspectos do Acesso dos Municípios ao HGPE na Televisão". Revista de Sociologia e Política, vol. 22, pp. 45-58.

JONES, Ruth. (1981), “State Public Campaign Finance: Implications for Partisan Politics". American Journal of Political Science, vol. 25, no 2, pp. 342-361.

JORGE, Vladimyr Lombardo. (1997), “Os Meios de Comunicação de Massa nas Campanhas Eleitorais". Comunicação \& Política, vol. 4, no1, pp. 126-133.

KAPLAN, David. (2009), Structural Equation Modeling. Foundations and Extensions. (2aㅡ ed.). Thousand Oaks, CA, Sage Publications.

KERBAUY, Maria Teresa Micely. (2000), A Morte dos Coronéis: Politica Interiorana e Poder Local. São Paulo, Cultura Acadêmica Editora.

KINZO, Maria D’Alva. (2005), “Os Partidos no Eleitorado: Percepções Públicas e Laços Partidários no Brasil”. Revista Brasileira de Ciências Sociais, vol. 20, no 57, pp. 65-82.

LAVAREDA, Antônio; TELLES, Helcimara de S. (orgs.). (2011), Como o Eleitor Escolhe seu Prefeito: Campanha e Voto nas Eleições Municipais. São Paulo, FGV Editora.

LLERAS, Christy. (2005), “Path Analysis”, in K. Kempf-Leonard (org.) (3a ed.). Encyclopedia of Social Measurement. Texas, University of Texas Press, pp. 25-30.

MAINWARING, Scott. (1995), "Brazil: Weak Parties, Feckless Democracy", in S. Mainwaring; T. Scully (orgs.), Building Democratic Institutions: Party Systems in Latin America. Stanford, Stanford University Press.

(1998), “Electoral Volatility in Brazil". Party Politics, vol. 4, no 4, pp. 523-545.

PEIXOTO, Vitor de Moraes. (2010), Eleições e Financiamento de Campanhas no Brasil. Tese (Doutorado em Ciência Política), Iuperj, Rio de Janeiro.

PEREIRA, Carlos; RENNÓ, Lucio. (2001), “O que é que o Reeleito Tem? Dinâmicas Político-institucionais Locais e Nacionais nas Eleições de 1998 para a Câmara dos Deputados". DADOS - Revista de Ciências Sociais, vol. 44, no 2, pp. 133-172.

PESTANA, Maria Helena; GAGEIRO, João Nunes. (2003), Análise de Dados para Ciências Sociais. A Complementaridade do SPSS. Lisboa, Edições Silabo. 


\section{Bruno Wilhelm Speck e Emerson Urizzi Cervi}

ROSEN, Ruth S. (1981), "State Public Campaign Finance: Implications for Partisan Politics". American Journal of Political Science, vol. 25, no 2, pp. 342-360.

SAMUELS, David. (2001), "Incumbents and Challengers on a Level Playing Field". The Journal of Politics, vol. 63, no 2, pp. 569-584.

(2002), "Pork Barreling is not Credit Claiming or Advertising: Campaign Finance and the Source of the Personal Vote in Brazil". The Journal of Politics, vol. 64, no 3, pp. 845-863.

SANTOS, Rodrigo D. (2011), Grandes Empresários e Sucesso Eleitoral nas Eleições de 2002, 2006 e 2010. Trabalho apresentado no 35o Encontro Anual da Anpocs, Caxambu, 24-28 de outubro.

SCHMITT, Rogério; CARNEIRO, Leandro Piquet; KUSCHNIR, Karina. (1999), “Estratégias de Campanha no Horário Gratuito de Propaganda Eleitoral em Eleições Proporcionais". DADOS - Revista de Ciências Sociais, vol. 42 no 2, pp. 277-301.

SILVEIRA, Bernardo S. da; MELLO, João Manoel Pinho de. (2011), “Campaign Advertising and Election Outcomes: Quasi-Natural Experiment Evidence from Gubernatorial Elections in Brazil". Textos para Discussão no 550, Departamento de Economia, PUC-Rio.

SPECK, Bruno W. (2005), “Reagir a escândalos ou perseguir ideais? A regulação do financiamento político no Brasil". Cadernos Adenauer, Ano 6, no 2, pp. 123-159.

; BRASILIENSE, José Mario (orgs.). (2013), “O Desempenho de Candidatos, Partidos e Coalizões nas Eleições Municipais de 2012". Cadernos Adenauer, no 2.

SPECK, Bruno W.; CAMPOS, Mauro Macedo. (2014), “Incentivos para a Fragmentação e a Nacionalização do Sistema Partidário a Partir do Horário Eleitoral Gratuito no Brasil". Teoria \& Pesquisa, vol. 23, no 2, pp. 12-40.

SPECK, Bruno W.; MANCUSO, Wagner P. (2011), O Financiamento Político nas Eleições Brasileiras de 2010: Um Panorama Geral. Trabalho apresentado no 35o Encontro Anual da Anpocs, Caxambu, 24-28 de outubro.

(2013), “O que Faz a Diferença? Gastos de Campanha, Capital Político, Sexo e Contexto Municipal nas Eleições para Prefeito em 2012". Cadernos Adenauer, no 2, pp. 109-126.

. (2014), "A Study on the Impact of Campaign Finance, Political Capital and Gender on Electoral Performance". Brazilian Political Science Review, vol. 8, № 1, pp. 34-57.

TAAGEPERA, Rein; SHUGART, Matthew Soberg. (1989), Seats \& Votes: The Effects \& Determinants of Electoral Systems. New Haven, Yale University Press. 


\section{RESUMO}

Dinheiro, Tempo e Memória Eleitoral: Os Mecanismos que Levam ao Voto nas Eleições para Prefeito em 2012

O artigo analisa o peso do tempo de propaganda e financiamento eleitoral nas disputas majoritárias locais no Brasil. Dialogamos com a literatura sobre o papel dos recursos financeiros e o tempo de propaganda gratuita nas eleições brasileiras, bem como com os estudos sobre a dinâmica da disputa eleitoral no âmbito municipal. Em termos metodológicos usamos regressão linear múltipla e análise de trajetória. A primeira mostra que a votação em 2012 é efeito da memória eleitoral a partir do desempenho do partido em 2008, do volume de recursos financeiros e do tempo de horário eleitoral na campanha de 2012. O peso destes fatores varia em função do tamanho dos municípios. A análise de trajetória permite identificar com mais clareza os mecanismos causais que atuam entre variáveis.

Palavras-chave: eleições municipais; prefeito; financiamento; horário eleitoral; path analysis

\section{ABSTRACT \\ Money, Time and Electoral Memory: The Mechanisms that Define the Vote in Mayoral Elections in 2012}

This article analyzes the influence of ads and electoral financing in majoritarian local disputes in Brazil. We dialogue with the literature on the role of financial resources and the time of unpaid advertisements in Brazilian election, as well as with the studies on the dynamics of electoral disputes at the municipal level. In methodological terms, we employed multiple linear regression and path analysis. The first shows that the 2012 vote was an effect of the electoral memory based on the performance of the party in 2008, de volume of financial resources and the time of electoral ad slots in the 2012 campaign. The influence of these factors varies according to the size of each municipality. Path analysis makes it possible to identify more clearly the causal determinants among the variables.

Keywords: municipal elections; mayor; financing; electoral television slots; path analysis

DADOS - Revista de Ciências Sociais, Rio de Janeiro, vol. 59, nº 1, 2016 


\section{RÉSUMÉ}

Argent, Temps et Mémoire Électorale: Les Mécanismes à l'Origine du Vote aux Élections Municipales de 2012

Cet article analyse le poids du temps imparti dans les campagnes audiovisuelles officielles et du financement électoral lors des scrutins majoritaires locaux au Brésil. Nous avons établi un dialogue avec la littérature sur le rôle des ressources financières et du temps de campagne audiovisuelle officielle dans les élections brésiliennes, ainsi qu'avec les études sur les dynamiques $d u$ jeu électoral au niveau municipal. En termes méthodologiques, nous avons eu recours à l'analyse de trajectoire et à la régression linéaire multiple. Celle-ci a permis de montrer que le scrutin de 2012 a été l'effet de la mémoire électorale relative aux performances des partis en 2008, du volume disponible de ressources financières et du temps de campagne audiovisuelle officielle en 2012. Le poids de ces facteurs varie en fonction de la taille des communes. L'analyse de trajectoire permet quant à elle d'identifier plus clairement les mécanismes causals en œuvre parmi ces variables.

Mots-clés: élections municipales; maire; financement; campagne audiovisuelle officielle; path analysis

\section{RESUMEN}

Dinero, Tiempo y Memoria Electoral: Los Mecanismos que Definen el Voto en las Elecciones para Alcalde en 2012

Este artículo analiza el peso del tiempo de propaganda y financiación electoral en las disputas mayoritarias locales en Brasil. Establecemos un diálogo con la literatura sobre el papel de los recursos financieros y el tiempo de propaganda gratuita en las elecciones brasileñas, bien como con el debate sobre la dinámica de la contienda electoral en el ámbito municipal. En términos metodológicos, utilizamos regresión linear múltiple y análisis de trayectoria. La primera muestra que la votación en 2012 está relacionada a la memoria electoral a partir de la performance del partido en 2008, del volumen de recursos financieros y del tiempo de horario electoral en la campaña de 2012. El peso de estos factores cambia según el tamaño de los municipios. Por otro lado, el análisis de la trayectoria permite identificar con mayor claridad los mecanismos causales que actúan entre las variables.

Palabras clave: elecciones municipales; alcalde; financiación; horario electoral; path analysis 